\title{
Comparison of qPCR and Metabarcoding Methods as Tools for the Detection of Airborne Inoculum of Forest Fungal Pathogens
}

\author{
Anne Chandelier, ${ }^{1, \dagger}$ Julie Hulin, ${ }^{2}$ Gilles San Martin, ${ }^{1}$ Frédéric Debode, ${ }^{1}$ and Sébastien Massart ${ }^{3}$ \\ ${ }^{1}$ Walloon Agricultural Research Centre, Department of Life Sciences, B-5030 Gembloux, Belgium \\ ${ }^{2}$ Walloon Agricultural Research Centre, Department of Valorisation of Agricultural Products, B-5030 Gembloux, Belgium \\ ${ }^{3}$ Liege University Gembloux Agro-Bio Tech, TERRA, Integrated and Urban Plant Pathology Laboratory, B-5030 Gembloux, Belgium \\ Accepted for publication 21 August 2020.
}

\begin{abstract}
Forest diseases caused by invasive fungal pathogens are becoming more common, sometimes with dramatic consequences to forest ecosystems. The development of early detection systems is necessary for efficient surveillance and to mitigate the impact of invasive pathogens. Windborne spores are an important pathway for introduction of fungal pathogens into new areas; the design of spore trapping devices adapted to forests, capable of collecting different types of spores, and aligned with development of efficient molecular methods for detection of the pathogen, should help forest managers anticipate new disease outbreaks. Two types of Rotorod samplers were evaluated for the

transcribed spacer sequences using a new bioinformatic pipeline, FungiSearch, developed for diagnostic purposes. Validation of the pipeline was conducted on mock communities of 10 fungal species belonging to different taxa. Although the sensitivity of the new HTS pipeline was lower than the specific qPCR, it was able to detect a wide variety of fungal pathogens. FungiSearch is easy to use, and the reference database is updatable, making the tool suitable for rapid identification of new pathogens. This new approach combining spore trapping and HTS detection is promising as a diagnostic tool for invasive fungal pathogens.
\end{abstract} collection of airborne inoculum of forest fungal pathogens with a range of spore sizes in five forest types. Detection was by specific quantitative PCR (qPCR) and by high-throughput sequencing (HTS) of amplified internal
Keywords: FungiSearch, HTS, mycology techniques, real-time PCR, spore trap, surveillance
The globalization of trade and tourism, as well as climate changes, have increased the risk of spread of nonnative species, including forest fungal pathogens (Ramsfield et al. 2016; Sturrock et al. 2011). Some of these fungi are nonpathogenic in their native region because they have coevolved with their host (Stenlid et al. 2011). However, once dispersed to new areas, the diseases caused by these invasive pathogens may have a direct economic impact by reducing timber or nursery stock production or through imposed trade restriction (Klapwijk et al. 2016). The diseases can also cause changes in natural forest ecosystems by threatening the survival of forest species (Chornesky et al. 2005; Lovett et al. 2006; Sache et al. 2011).

Fungi are the most damaging pathogens in forests. Hymenoscyphus fraxineus on European ash (Kowalski 2006), Cryphonectria parasitica on chestnut (Rigling and Prospero 2018), or Ophiostoma novo-ulmi (Allen and Humble 2002; Brasier 1991), which occur in Europe and North America, are examples of pathogenic fungi introduced to new areas and subsequently causing serious disease epidemics. The number of invasive fungal pathogens in Europe has increased dramatically in the last 30 years (Santini et al. 2013), and this trend is expected to continue in the future. Although quarantine measures restrict the movement of plants between continents, they have no effect on aerially dispersed fungal pathogens, especially those with propagules able to travel over very long distances (Brown

†Corresponding author: A. Chandelier; a.chandelier@cra.wallonie.be

Funding: This research was conducted in the framework of the Biodiversa project RESIPATH.

*The $e$-Xtra logo stands for "electronic extra" and indicates that two supplementary tables, four supplementary figures, and supplementary materials are published online.

The author(s) declare no conflict of interest.

(C) 2021 The American Phytopathological Society and Hovmøller 2002). Moreover, introduction pathways for new diseases of forest trees are not always clearly identified, weakening pest risk analyses (Weber 2010). Surveillance and early detection systems adapted to forest environments are needed to prevent the establishment of invasive fungal pathogens in new regions and to ensure timely intervention to prevent disease escalation. Sentinel trees (Vettraino et al. 2015), remote sensing (Chen and Meentemeyer 2016), and citizen scientists (Crocker et al. 2020) are all promising approaches for monitoring forest diseases. Besides these methods, spore samplers, including air and rain samplers, are also of potential value to collect propagules of fungal pathogens (Chen et al. 2018). Various types of spore traps are available to sample airborne inoculum of plant fungal pathogens (West and Kimber 2015). For plant biosecurity purposes, spore traps must fulfill specific requirements, notably in terms of reproducibility and reliability. Moreover, any spores collected by the trap should be identified rapidly and accurately (Jackson and Bayliss 2011), meaning that the postsampling detection method must be able to efficiently detect a large range of fungal species. Spore trapping combined with quantitative PCR (qPCR) has proven to be efficient in the detection of invasive forest fungal pathogens (Chandelier et al. 2014; Dvořák et al. 2017; Grosdidier et al. 2018; Quesada et al. 2018). Although these molecular methods are adapted to the early detection of forest pathogens, they can detect only one or very few species at a time. Moreover, PCR identifies only known pathogen strains and can sometimes generate false negative results in cases of variability between strains of the pathogen at the primer or probe hybridization sites, as was found with $H$. fraxineus (Drenkhan et al. 2017).

High-throughput sequencing (HTS) is a powerful technique to analyze fungal communities in different environments (Lindahl et al. 2013; Purahong et al. 2019; Tedersoo et al. 2019), notably in the air (Banchi et al. 2019). HTS has been used for plant virus (Massart et al. 2014) and bacteria (Oluseyi Osunmakinde et al. 2019) detection. However, HTS is still in its infancy as a diagnostic tool for fungal plant pathogens (Olmos et al. 2018) because each 
step of the procedure is subject to methodological errors that can lead to misinterpretation (Aguayo et al. 2018; Lindahl et al. 2013).

For diagnostic purposes, it is essential to implement rigorous and validated protocols to limit these biases (Martin et al. 2016; Nilsson et al. 2019; Tedersoo et al. 2019). Targeted amplification of the internal transcribed spacer regions (ITS1 or ITS2) of the ribosomal RNA gene has been used to analyze mycobiome diversity because the ITS1 and ITS2 are hypervariable regions flanked by highly conserved sequences on which to design universal PCR primers able of amplify from a wide range of fungi (Schoch et al. 2012). However, if the protocol is to be used as an effective diagnostic method, a correct taxonomic assignment at the species level, or sometimes at an infraspecific level, is needed.

The detection of fungal pathogens by combining spore trapping and HTS has been described for the detection of Diplodia corticola (Bérubé et al. 2018) and for screening of exotic forest pathogens collected on Rotorod samplers in Canada (Tremblay et al. 2018). In Italy, a survey of fungal pathogens was conducted by placing spore traps on the roofs of buildings (Banchi et al. 2018). However, the HTS pipelines used in these studies needed high computational capacity as well as highly trained and skilled personnel. Also, HTS pipelines are linked to reference databases that cannot be updated easily and directly by diagnosticians. As new fungal species are discovered at an increasing rate (Blackwell 2011), the lack of reference fungal databases that are regularly updated constitutes a major constraint to the use of HTS-based metabarcoding techniques for species identification.

The first objective of the study was to evaluate Rotorod samplers with two types of rods for the collection of fungal spores with a range of sizes in the forest. The second objective was to compare the results of specific qPCR detection with HTS analysis by using a new user-friendly bioinformatic pipeline, FungiSearch, that is able to identify sequence reads at the species taxonomic level and has an updatable reference database. The third objective was to document airborne fungal diversity in different types of forest in Belgium.

\section{MATERIALS AND METHODS}

Reference fungal pathogens. Three fungal pathogens that produce airborne spores of contrasting size were selected. Heterobasidion annosum produces small spores $(4.8 \times 3.5 \mu \mathrm{m}$ [conidia] and $3.5 \times 2.5 \mu \mathrm{m}$ [basidiospores) (Shaw and Florance 1979) mainly in the spring and the autumn (Sylvestre-Guinot and Delatour 1978). H. fraxineus produces medium-size ascospores (13.5 to $24.8 \times 3.5$ to $5.5 \mu \mathrm{m}$ ) (Baral and Bremmann 2014), mainly in the summer (Chandelier et al. 2014). Conidia are produced in winter. However, they are sticky and less adapted to airborne dispersal. Erysiphe alphitoides produces large conidia (25 to $45 \times$ 13 to $25 \mu \mathrm{m}$ ) (Takamatsu et al. 2007) in summer from primary infections caused by ascospores (13.4 to $22.6 \times 8.8$ to $14.1 \mu \mathrm{m}$ ) in the spring (Marçais et al. 2009).

Forest sites. Five forest stands were selected in the southern region of Belgium. One plot (Floriffoux, N50.467479, E4.756892) was a mixed forest composed of Quercus petraea (primary species), Picea abies, Pseudotsuga menziesii, Betula pendula, Fraxinus excelsior, Castanea sativa, and Populus sp. (mixed forest). Four other plots corresponded to forest sites with one or two dominant tree species (considered low-diversity forests): Maissin (N49.948967, E5.179482) was a Douglas fir plantation with numerous spruce stumps on which fruiting bodies of $H$. annosum were frequently observed; Bievre (N49.972841, E5.041161) was an oak (Quercus robur) forest where E. alphitoides was prevalent; Morialme (N50.269970, E4.546702) was a wetland where Fraxinus excelsior was the most common tree species. Most of the ash trees had symptoms of ash dieback caused by $H$. fraxineus; Carlsbourg (N49.882985, E5.089853) was a Douglas fir plantation but had no visible fruiting bodies of $H$. annosum or symptoms of any other diseases.
Spore trapping systems. The spore trapping systems were placed $1 \mathrm{~m}$ above the ground in close proximity ( $<1.5 \mathrm{~m}$ apart) to each other in the forest stands. Rotorod samplers (Edmonds 1972) consisted of an "in house" spore trap $(2,400 \mathrm{rpm}$, sampling rate of about 70 liters/min, Supplementary Fig. S1A) (Chandelier et al. 2014). To evaluate the influence of rod width on collection efficiency, two types of collection rod were tested (Supplementary Fig. S1B). Type 1 was a match ( $2.5 \mathrm{~mm}$ wide), and type 2 was a flat nail (1.25 mm wide). Double-sided tape (Tesa, Double-Sided Tape Universal, Brussels, Belgium) was placed on the leading face of the rods so that the collection surface area was the same $\left(50 \mathrm{~mm}^{2}\right)$ for both the match $(2.5 \mathrm{~mm} \times 20 \mathrm{~mm})$ and the flat nail $(1.25 \mathrm{~mm} \times$ $40 \mathrm{~mm}$ ). At the end of a collection period, the match rods were placed in sterile $2.0-\mathrm{ml}$ microcentrifuge tubes and the nail rods in sterile 5-ml round-bottom snap cap tubes. A Burkard 7-day volumetric sampler (Burkard Manufacturing Co., Rickmansworth, UK) was operated in the mixed forest (Floriffoux) to determine the pattern of spore dispersal for the fungi under study. The spores were collected on Melinex tape coated with a thin layer of Vaseline (VWR, Oud-Heverlee, Belgium) applied with a brush in a laminar flow cabinet and immediately placed in a box to avoid contaminants before use. The Burkard trap was operated at a rate of 10 liter/min as described by Calderon et al. (2002). At the end of the collection period, the Melinex tape was cut into seven daily sections in the laminar flow cabinet, with each section placed in a $1.5-\mathrm{ml}$ tube. Field samples were stored at $-20^{\circ} \mathrm{C}$ until further processing.

In Floriffoux, seven samplings were taken with the Burkard sampler, and 14 samplings were taken with the Rotorod samplers (two Rotorods with nails and two with matches for each sampling period) in 2014. The Burkard sampler was used from day 1 to day 15 (4/15 to $4 / 29,5 / 14$ to $5 / 28,6 / 4$ to $6 / 18,7 / 11$ to $7 / 25,7 / 30$ to $8 / 13,9 / 1$ to $9 / 15$, and $9 / 24$ to $10 / 8$ ). The four Rotorod samplers were operated simultaneously from day 1 to day 3 , and from day 13 to day 15 of the Burkard collection period. In 2015, 11 samplings were conducted ( $6 / 4$ to $6 / 6,7 / 8$ to $7 / 10,7 / 15$ to $7 / 17,7 / 22$ to $7 / 24,7 / 29$ to $7 / 31,8 / 5$ to $8 / 7,8 / 11$ to $8 / 13,8 / 26$ to $8 / 28,9 / 2$ to $9 / 4,9 / 9$ to $9 / 11,9 / 23$ to $9 / 25$ ) using only Rotorod samplers with nails. At the remaining four sites, tests with Rotorod samplers (nails and matches) were conducted in 2014 during periods of spore release for the three pathogens under study according to the literature (Maissin [H. annosum], 9/2 to 9/4, $10 / 4$ to $10 / 6$ ); Bievre [E. alphitoides], $6 / 25$ to $6 / 27,7 / 7$ to $7 / 9$; Morialme [H. fraxineus], $7 / 23$ to $7 / 25,8 / 5$ to $8 / 7$; Carlsbourg [H. annosum], $5 / 20$ to $5 / 22,6 / 3$ to $6 / 05$ ).

Microscopy. The rods (match or nail) from the Rotorod samplers used during two periods in 2014 in Maissin (9/2 to 9/4, $10 / 4$ to $10 / 6)$ and Bièvre $(6 / 25$ to $6 / 27,7 / 7$ to $7 / 9)$ were soaked in cotton blue for $30 \mathrm{~s}$. The impaction surfaces were mounted on microscopic slides and spores were counted over two randomly selected areas of $1 \times 2 \mathrm{~mm}$ on each impaction surface via an inverted microscope. Spores of $<10 \mu \mathrm{m}$ (small spores), and those $>20 \mu \mathrm{m}$ (large spores) were counted. A linear mixed model with logtransformed counts as the response variable, the rod and site as fixed effects, and the collection date as a random factor was performed separately for each spore size in the lme4 package (Bates et al. 2015) in R (version 3.6.2, R Core Team 2019).

DNA extraction. The remaining tubes containing rods or Melinex segments were vortexed at high speed for $30 \mathrm{~s}$ with $0.5 \mathrm{~mm}$ zirconia/silica beads (200 mg, BioSpec Products, Lab Services BV, Breda, The Netherlands) in $500 \mu$ l Nonidet P-40 Substitute $0.1 \%$ (Sigma Aldrich, Overijse, Belgium). The tubes were placed at $-20^{\circ} \mathrm{C}$ for $5 \mathrm{~min}$ and vortexed again at high speed for $30 \mathrm{~s}$. TEX lysis buffer (Tris $100 \mathrm{mM} \mathrm{pH} 8.0$, EDTA $20 \mathrm{mM}, \mathrm{NaCl} 1.4 \mathrm{M}, \mathrm{CTAB} 2 \%$, and PVP-K30 2\%) $(500 \mu \mathrm{l})$ and proteinase $\mathrm{K}(40 \mu \mathrm{l}$, solution at $1 \mathrm{mg} / \mathrm{ml}$ ) were added to the tube. The DNA was extracted with a High Pure Template Preparation Kit (Roche Diagnostics, Mannheim, Germany) according to the manufacturer's recommendations. The DNA was eluted with $150 \mu \mathrm{l}$ of elution buffer. DNA was also extracted from mycelium of $H$. annosum, $H$. fraxineus, and 
Cladosporium cladosporioides grown on potato dextrose agar and from spores of E. alphitoides collected on oak leaves with the same DNA extraction kit. DNA quantification was performed with a Quant-iT PicoGreen dsDNA Assay Kit (ThermoFisher, Merelbeke, Belgium).

qPCR and standard curves. H. annosum sensu lato and $H$. fraxineus were detected by previously described qPCR methods (Bodles et al. 2006; Chandelier et al. 2010). A qPCR diagnostic has been developed to distinguish $E$. alphitoides from E. quercicola, the main Erysiphe species infecting oak in Europe (Marçais et al. 2017) (Supplementary Materials). An additional qPCR targeting Cladosporium spp. (Zeng et al. 2006) was included in the study because species from this fungal genus produce large numbers of small conidia (Bensch et al. 2015) throughout the year and can be used as a control for estimating trapping efficiency as well as for testing the DNA extraction step ("process control"). For the four fungal targets, qPCR was performed in a total volume of $20 \mu \mathrm{l}$ with a StepOne Plus thermocycler (Thermo Fisher Scientific, Merelbeke, Belgium). Each PCR reaction contained $1 \times$ PCR Core kit buffer (Eurogentec, Seraing, Belgium), $\mathrm{MgCl}_{2}(5 \mathrm{mM})$, dNTPs $(0.2 \mathrm{mM})$, forward and reverse primer $(0.25 \mu \mathrm{M})$, TaqMan probe $(0.25 \mu \mathrm{M})$, Taq DNA polymerase $(0.75 \mathrm{U})$, and $5 \mu \mathrm{l}$ of DNA. The PCR conditions were $95^{\circ} \mathrm{C}, 10 \mathrm{~min} ; 95^{\circ} \mathrm{C}, 15 \mathrm{~s}$; and $X^{\circ} \mathrm{C}, 1 \mathrm{~min}(40 \times)$ where $X$, the annealing temperature, was $60^{\circ} \mathrm{C}$ for $H$. annosum, $H$. fraxineus, and Cladosporium spp. and $66^{\circ} \mathrm{C}$ for E. alphitoides. The fluorescence threshold was set at 0.2 in all cases.

Serial dilutions of genomic DNA extracted from mycelium (H. annosum, $H$. fraxineus, $C$. cladosporioides) and from spores (E. alphitoides) (from $1 \mathrm{ng}$ to $10 \mathrm{fg}$ per PCR, three technical replicates per concentration level) were made. DNA was also extracted from serial dilutions of spores collected from fruiting bodies of $H$. annosum growing on stumps of Norway spruce, from apothecia of $H$. fraxineus on ash petioles, from ascomata of E. alphitoides on oak leaves, or from mycelium of $C$. cladosporioides cultured in Petri dishes. The spores were diluted with $0.1 \%$ Nonidet P-40 Substitute and counted with a Burker cell (three replicates per spore concentration). The cycle threshold $(\mathrm{Ct})$ values resulting from the corresponding qPCRs were used to establish standard curves, allowing the transformation of the $\mathrm{Ct}$ values into DNA concentrations or spore equivalents.

The numbers of spores collected on Rotorod samplers in 2014 were log-transformed (which improved distribution of the residuals), and a comparison between match and nail Rotorods was made via linear regression considering the type of rod (match or nail) and the target (species), and the interaction as the fixed effects, and the collection dates and location as random effects. Linear regressions were performed separately for each target (in the R package lme4).

To assess the recovery rate with the different spore traps, qPCRs were conducted with DNA extracted from spores of $H$. annosum (from 360 to $3.6 \times 10^{5}$ spores per qPCR), H. fraxineus (from 2 to 200 spores per qPCR), and C. cladosporioides (from 1,700 to $1.7 \times 10^{6}$ spores per qPCR) spiked onto the impaction material (nail or match covered with double-sided tape and Melinex tape) and allowed to dry for $2 \mathrm{~h}$, and from DNA extracted from the same concentration of spores in the suspension. The results were compared via linear models (one-way analysis of variance in $\mathrm{R}$ ), with the $\mathrm{Ct}$ value as the response variable and the impaction material as the explanatory variable.

Mock communities of fungi for HTS analysis. A mock community (MC) was prepared from 10 fungal species (Table 1). Total DNA was extracted from mycelium with a the High Pure Template Preparation Kit (Roche Diagnostics, Mannheim, Germany), and quantification was performed with a Quant-iT PicoGreen dsDNA Assay Kit (ThermoFisher, Merelbeke, Belgium). Identification of species was confirmed by performing Sanger sequencing on the ITS5 to ITS4 region (White et al. 1990) and doing a BLAST search against the National Center for Biotechnology Information (NCBI) database. The DNA sequence corresponding to Eutypa lata (CBS101932) was 100\% homologous to Eutypella caricae (accession JX241652) but did not match with E. lata. ClustalW multiple alignment of ITS sequences available in NCBI for $E$. lata and E. caricae confirmed this result. The strain CBS101932 was therefore considered to be E. caricae.

PCR for HTS analysis. Three primers sets targeting the ITS1 (primer sets 1 and 3) or ITS2 (primer set 2) regions (Gardes and Bruns 1993; Toju et al. 2012; White et al. 1990), to which Illumina adapter overhang nucleotide sequences were added (Supplementary Table S1), were compared with DNA from the 10 species in the MC at 100 pg DNA per community (MC1). The modified primers (purified by high-performance liquid chromatography) were synthesized by Eurogentec (Seraing, Belgium). The first-stage PCR with the three primer pairs was conducted with a T100 Biorad thermocycler. The PCR reactions $(25 \mu \mathrm{l})$ consisted of $1 \times$ KAPA HiFi HotStart Ready Mix (Sopachem, Nazareth, Belgium), $200 \mathrm{nM}$ of forward primer, $200 \mathrm{nM}$ of reverse primer, and $5 \mu \mathrm{l}$ of DNA or $5 \mu \mathrm{l}$ of sterile ultrapure water (negative control). Thermal cycling conditions included a first step at $95^{\circ} \mathrm{C}$ for $3 \mathrm{~min}$, followed by 25 cycles of denaturation at $95^{\circ} \mathrm{C}$ for $30 \mathrm{~s}$, annealing at $55^{\circ} \mathrm{C}$ for $30 \mathrm{~s}$

TABLE 1. List of fungal species used in mock communities MC1 to MC7, their characteristics, and size of amplification products generated with the three PCR primer sets (PS) used in high-throughput sequencing

\begin{tabular}{|c|c|c|c|c|c|c|c|c|c|}
\hline \multirow[b]{2}{*}{ Fungal species } & \multirow[b]{2}{*}{ Division (order) } & \multirow[b]{2}{*}{ Code } & \multirow[b]{2}{*}{ Collection } & \multirow[b]{2}{*}{ Host } & \multirow[b]{2}{*}{ Year } & \multirow[b]{2}{*}{ Origin } & \multicolumn{3}{|c|}{$\begin{array}{l}\text { PCR product } \\
\text { (bp) }\end{array}$} \\
\hline & & & & & & & PS1 & PS2 & PS3 \\
\hline Armillaria gallica & Basidiomycota (Agaricales) & 3343 & INRA $^{\mathrm{a}}(\mathrm{A} 63)$ & Corylus avellana & 2005 & France & 346 & $565^{\mathrm{b}}$ & 357 \\
\hline Eutypella caricae ${ }^{\mathrm{c}}$ & Ascomycota (Xylariales) & 3841 & $\mathrm{CBS}^{\mathrm{d}}(101932)$ & Fraxinus excelsior & 1998 & The Netherlands & 298 & $338^{\mathrm{e}}$ & 306 \\
\hline Fusarium lateritium & Ascomycota (Hypocreales) & 3821 & CRAW & F. excelsior & 2007 & Belgium & 260 & $345^{f}$ & 268 \\
\hline Ganoderma adspersum & Basidiomycota (Polyporales) & 4137 & CRAW & Fagus sylvatica & 2009 & Belgium & 311 & $375^{f}$ & 308 \\
\hline Heterobasidion annosum & Basidiomycota (Russulales) & $14 / 011$ & CRAW & Picea abies & 2014 & Belgium & 297 & $382^{\mathrm{b}}$ & 294 \\
\hline Hymenoscyphus fraxineus & Ascomycota (Helotiales) & 3817 & $\mathrm{CBS}^{\mathrm{b}}(122507)$ & F. excelsior & 2008 & Poland & 593 & $328^{\mathrm{e}}$ & 596 \\
\hline \multicolumn{10}{|l|}{ Nothophaeocryptopus } \\
\hline gaeumannii & Ascomycota (Pleosporales) & 4855 & CRAW & Pseudotsuga menziesii & 2015 & Belgium & 254 & $321^{\mathrm{e}}$ & 261 \\
\hline Ophiostoma novo-ulmi & Ascomycota (Ophiostomales) & 4547 & CRAW & Ulmus minor & 2013 & Belgium & 320 & $398^{\mathrm{b}}$ & 317 \\
\hline Trametes versicolor & Basidiomycota (Polyporales) & 3561 & CRAW & Quercus petraea & 2006 & Belgium & 294 & $372^{\mathrm{f}}$ & 303 \\
\hline Verticillium dahliae $e^{\mathrm{e}}$ & Ascomycota (Incertae sedis) & 3732 & CRAW & Acer campestre & 2008 & Belgium & 238 & $347^{f}$ & 245 \\
\hline
\end{tabular}

a INRA-Nancy collection, Champenoux (France), B. Marçais.

b Group 3 according to PCR product size with primer set 2 .

c Strain CBS101932 corresponds to Eutypella caricae instead of Eutypa lata based on internal transcribed spacer alignment of accessions available on the National Center for Biotechnology Information database.

d CBS-KNAW fungal collection, Utrecht, The Netherlands.

e Group 1 according to PCR product size with primer set 2 .

f Group 2 according to PCR product size with primer set 2 . 
and $72^{\circ} \mathrm{C}$ for $30 \mathrm{~s}$, and a final extension at $72^{\circ} \mathrm{C}$ for $5 \mathrm{~min}$. All other steps of the library preparation workflow were performed by DNA Vision (Charleroi, Belgium) according to the standard protocol from Illumina (MiSeq platform, 2 × 300 nt length; https:// support.illumina.com/documents/documentation/chemistry_ documentation/16s/16s-metagenomic-library-prep-guide-15044223b.pdf).

To assess the sensitivity, repeatability, and reproducibility of the HTS method with the selected PCR primer set (primer set 2), DNA from the 10 species of the MC were classified into three groups according to the size of their amplification product (Table 1) and pooled in different proportions (at 100,10, or 1 pg per community) according to the group to which they belonged (MC2 to MC7) (Supplementary Table S2). PCRs and sequencing were performed as described for MC1.

DNA extracted from Rotorod samplers with nails and placed in the forest in 2014 and 2015 were screened with primer set 2. Two HTS runs of 96 reactions were conducted, one for forest samples collected in 2014 (four sampling periods in the mixed forest and one sampling period in each of the low-diversity forests) and the second one for forest samples collected in the mixed forest in 2014 (three sampling periods already analyzed in run 1 and four sampling periods not analyzed in run 1) and 2015 (the 11 sampling periods). Negative controls (water) and MCs (in duplicate, sequenced independently) were introduced in both HTS runs (MC1A/B to $\mathrm{MC7A} / \mathrm{B}$ in HTS run 1 and MC2A/B to MC5A/B in HTS run 2). Raw sequences were deposited in the NCBI Sequence Read Archive database under Bioproject PRJNA604896 with accession numbers SAMN14001663 to SAMN14001737.

Bioinformatic analysis of the data. Demultiplexing and adaptor trimming were performed by DNA Vision with the standard pipeline from Illumina. The FASTQ files were analyzed with the newly developed FungiSearch pipeline. The paired reads were joined on the overlapping region, stripped (by removing 17 nucleotides at both ends corresponding to the $3^{\prime}$ end of the HTS PCR primers), and quality filtered with the USEARCH v11 pipeline (Edgar 2010). The UNOISE algorithm implemented in USEARCH v11, allowing identification of zero-radius operational taxonomic units (ZOTUs) (biological species; Edgar and Flyvbjerg 2015), and the classic UPARSE algorithm, identifying operational taxonomic units (OTUs) with 97\% identity (Edgar 2013), were evaluated. The UNOISE method of grouping sequences allows the resolution of closely related species that could be part of the same cluster with the UPARSE method (Edgar 2016). Taxonomic assignments were performed with BLAST by using a reference database constructed on 29 October 2019 from an extraction of 397,493 ITS fungal sequences from species available at NCBI. The percent identity (perc_identity), the query coverage (qcov_hsp_perc), and the total number of hits selected by BLAST for the analysis (max_target_ seqs [MTS]) were set at $99.5 \%, 85 \%$, and 1,000, respectively.

Three parameters were calculated for each assigned ZOTU/OTU: the percentage of reads (RA), the total number of accessions with the highest E-value in the reference database, and the hit proportion (HP). The HP is the ratio between the number of accessions corresponding to the species and the total number of accessions. A list of quarantine fungi or of fungi put on the alert list of the European Plant Protection Organization (EPPO; https://www. eppo.int/ACTIVITIES/quarantine_activities, list established on 18 June 2019) was integrated in the pipeline to inform the diagnostician of potential new introductions.

Two types of result tables are created. A summary table displays a list of the most probable species (based on their HP value) and their corresponding RA value for the different samples analyzed. A specific table (one for each sample) displays, for each assigned ZOTU/OTU, the RA value, an EPPO alert message (if any), the total number of accessions found in the reference database, and the list of probable species sorted by their HP value. Taxonomic assignments to the species level are considered at low risk of misinterpretation for species with an HP value $>0.75$. For species with an HP value $<0.75$, either one species could stand out from the others with a much higher HP value, or no species stands out from the others. In the latter case, species identification is not reliable (Supplementary Fig. S2).

The programs of the FungiSearch pipeline and the procedures to use the pipeline and to build a reference database are provided as a public figshare repository (https://figshare.com/articles/FungiSearch_zip/11826831). The FungiSearch pipeline runs under Windows using a conventional computer.

Interpretation of the HTS data. A cutoff of reads was determined for each HTS run considering the proportion of false positive results (sum of unexpected species/total number of species) and the proportion of false negative results (sum of expected species not detected/total number of expected species) in MCs. The normalization level was evaluated for each HTS run based on rarefaction curves in the R package vegan (Oksanen et al. 2019). Simpson's diversity index was calculated according to Simpson (1949). Repeatability and reproducibility of the HTS method were evaluated on log-transformed RA values of the MCs in duplicate (MC1A/B to MC7A/B) via linear regressions (in R). Diagnostic sensitivity and diagnostic specificity of the HTS method compared with specific qPCR were calculated according to EPPO (2018) on 47 forest samples collected in 2014 (the five forest stands) and 2015 (the mixed forest) for which data were available with the two detection methods. Presence or absence of the different fungal species (combination of HTS run 1 and run 2) identified in the forest samples was illustrated by a heat map. Similar species and samples were grouped based on their Jaccard distance and the Ward hierarchical clustering algorithm (ward.D2 method in R base hclust function). The number of groups ( $n=4$ for the samples and for the fungal species) was chosen based on the visual interpretation of the heat map.

\section{RESULTS}

qPCR limit of detection. The qPCRs for each of the four species (H. annosum, E. alphitoides, H. fraxineus, and Cladosporium spp.) were evaluated on serial dilutions of genomic DNA extracted from mycelium and from spores. Two of the tests (for

TABLE 2. Standard curves (linear regressions) and limits of detection (LOD, in fg genomic DNA or spore equivalent per quantitative PCR) for the four fungal species under study ${ }^{\mathrm{a}}$

\begin{tabular}{|c|c|c|c|c|c|c|c|}
\hline \multirow[b]{2}{*}{ Species } & \multirow[b]{2}{*}{ Target region } & \multicolumn{3}{|c|}{ Genomic DNA } & \multicolumn{3}{|c|}{ Spore } \\
\hline & & $\begin{array}{l}\text { Linear regression } \\
\text { solution }\end{array}$ & LOD (fg) & $\mathrm{Ct}_{\mathrm{LOD}}$ & $\begin{array}{l}\text { Linear regression } \\
\text { solution }\end{array}$ & $\begin{array}{l}\text { LOD } \\
\text { (spore) }\end{array}$ & $\mathrm{Ct}_{\mathrm{LOD}}$ \\
\hline Heterobasidion annosum & Single copy (laccase gene) & $-3.58 X+45.64$ & 100 & 37.62 & $-3.66 X+43.74$ & 50 & 37.5 \\
\hline Hymenoscyphus fraxineus & Multicopy (ITS) & $-3.46 X+38.44$ & 10 & 34.78 & $-3.44 X+35.26$ & 1 & 35.3 \\
\hline $\begin{array}{l}\text { Cladosporium } \\
\text { cladosporioides }\end{array}$ & $\begin{array}{l}\text { Multicopy (mitochondrial } \\
\text { DNA) }\end{array}$ & $-3.54 X+38.53$ & 10 & 35.35 & $-3.20 X+39.09$ & 10 & 35.9 \\
\hline
\end{tabular}

${ }^{a} \mathrm{Ct}_{\mathrm{LOD}}$, mean cycle threshold value (three replicates) at the limit of detection; ITS, internal transcribed spacer. 
H. annosum and E. alphitoides) had a limit of detection of $100 \mathrm{fg}$ of genomic DNA per PCR and a linearity over $5 \operatorname{logs}$, and the two other tests (for $H$. fraxineus and Cladosporium spp.) had a limit of detection of $10 \mathrm{fg}$ per PCR and a linearity over 6 logs (Table 2 ). The minimum number of spores detected per PCR ranged from 50 (H. annosum) to 1 (H. fraxineus) (Table 2 ).

Spore recovery from double-sided or Melinex tape spiked with spore suspensions. qPCR was conducted on DNA extracted from the spiked materials and from suspensions of spores of the same concentration. We found no significant differences between the average $\mathrm{Ct}$ values from spore suspensions and any of the corresponding substrates: tape on nail $(F=0.757, P=$ $0.387)$, tape on match $(F=0.473, P=0.498)$, and Melinex coated with Vaseline $(F=0.378, P=0.545)$. Based on these results, the standard curves established for spores in suspension were used for the four fungal species and the different substrates.

Temporal pattern of spore dispersal. Using a Burkard sampler, we collected spores continuously for 14 days over 7 periods in 2014 in the mixed forest (Floriffoux). H. annosum spores were collected at concentrations $\leq 50,000$ spores per trap over $24 \mathrm{~h}$, with the highest counts being observed at the end of the summer and in autumn. In contrast, there was a maximum daily collection of $<6,000$ spores of E. alphitoides. The highest numbers of E. alphitoides spores were observed in June, with smaller peaks in May and July. With $H$. fraxineus, very few spores were collected on some days in June, and the highest numbers of spores were observed in July and August (a maximum of 2,249 spores per trap over $24 \mathrm{~h}$ in August) (Fig. 1). Spores of Cladosporium spp. were detected every day during the collection period $(\mathrm{Ct}<31)$ (data not shown).

Comparison between rod type on Rotorod samplers. Spores were collected with Rotorod samplers using rods of two widths (the nail was narrower than the match) in five forest stands over different periods in 2014. The Pearson correlation coefficient between the log-transformed number of spores for the two types of
Rotorod samplers considering all collection periods and the four fungal targets was high $(r=0.939, P<0.0001)$ (Fig. 2). A range of spore concentrations was observed with $H$. annosum, $H$. fraxineus, and $E$. alphitoides in the different samples, whereas the concentration of Cladosporium spp. was consistently high in all samples (Fig. 2). Four Rotorod samplers failed during the tests because of motor or battery problems. For these experiments, the $\mathrm{Ct}$ value for Cladosporium spp. was undetermined (three cases) or was very close $(\mathrm{Ct}=38.96)$ to the end of the PCR run (data not shown).

Using linear mixed models, we observed differences between rods (nails and matches) (likelihood-ratio $[\mathrm{LR}]=8.439, P=0.029$ ) and between targets $(\mathrm{LR}=2.105, P<0.0001)$. When each target was analyzed separately, narrow rods (nails) were found to collect

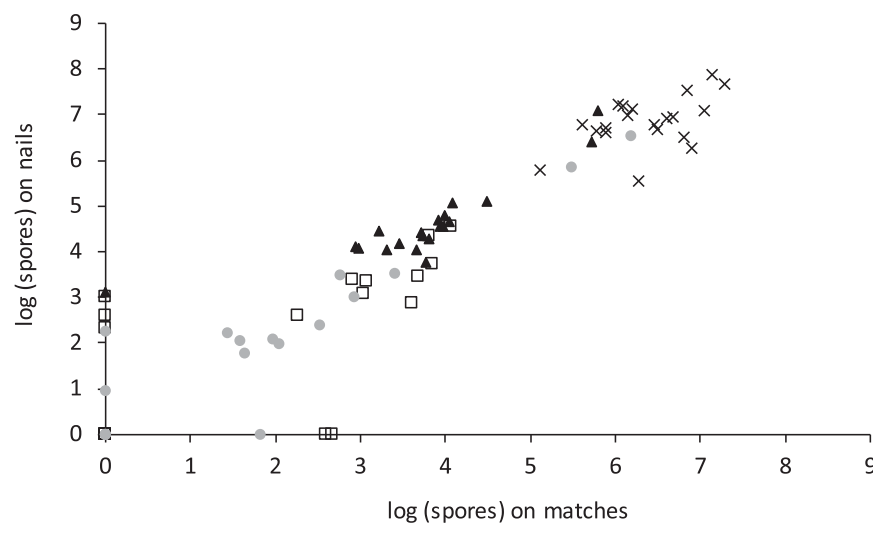

$\Delta$. annosum $\square$ E. alphitoides $\quad$ H. fraxineus $\times$ Cladosporium spp.

Fig. 2. Comparison between log-transformed concentration of spores of Heterobasidion annosum, Erysiphe alphitoides, Hymenoscyphus fraxineus, and Cladosporium spp. collected on matches or nails used as rods on the Rotorod spore traps in 5 Belgian forest sites in 2014 (mean of two replicates).
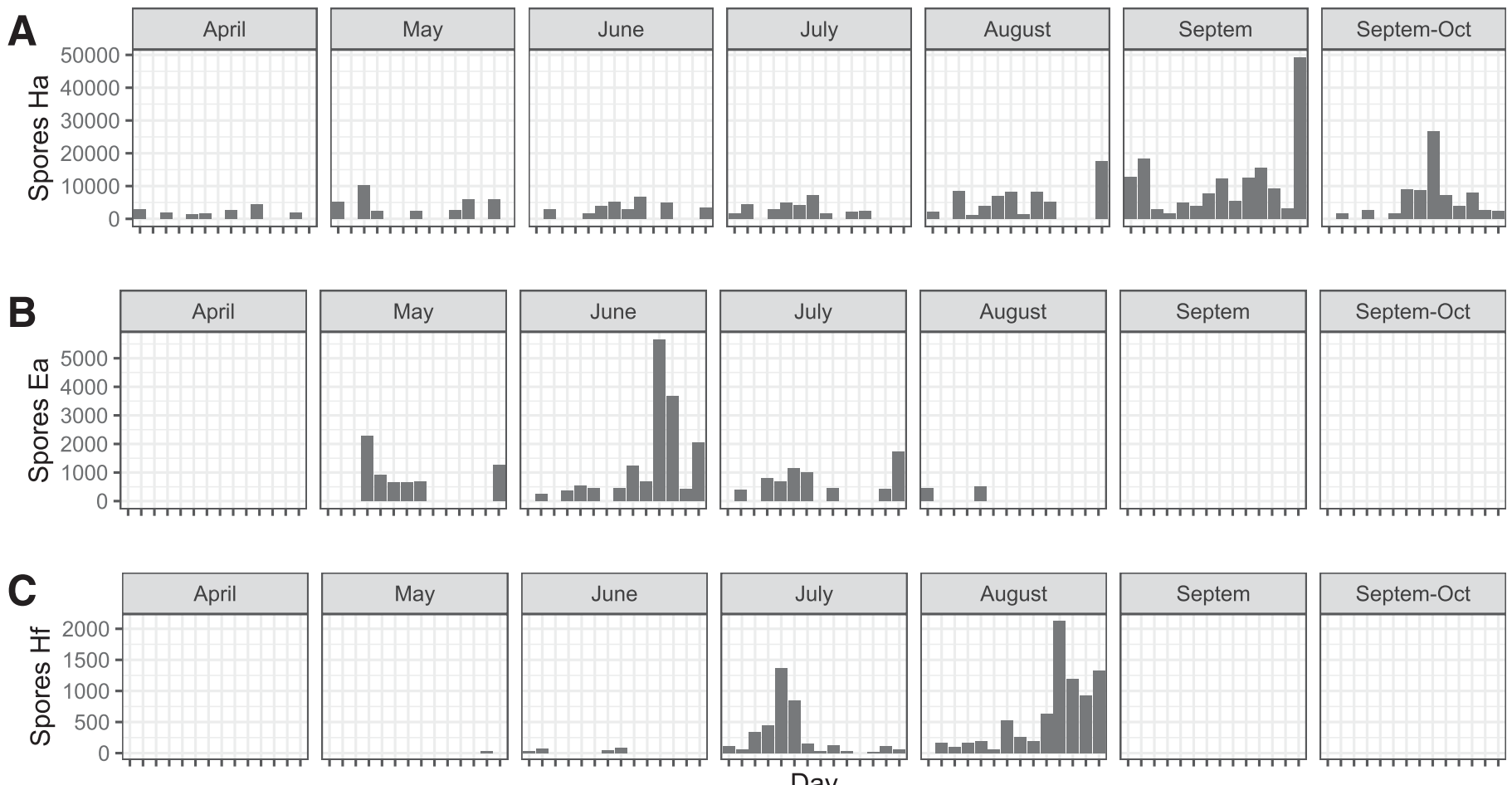

Fig. 1. Temporal pattern of spore dispersal for the three fungal pathogens (A, Heterobasidion annosum [Ha]; B, Erysiphe alphitoides [Ea]; C, Hymenoscyphus fraxineus $[\mathrm{Hf}]$ ) based on the collection of spores with a Burkard sampler in the Floriffoux mixed forest in 2014. There were 7 collection periods of 14 days each (April [04/15 to 04/29], May [05/14 to 05/28], June [06/04 to 06/18], July [07/11 to 07/25], August [07/30 to 08/13], September [09/01 to 09/15], and September/ October [09/24 to $10 / 08])$. 
greater numbers of spores than the wide rods (matches) for H. annosum (LR $=21.420, P<0.0001$ ) and Cladosporium spp. (LR $=12.912, P<0.0001)$ but not for $E$. alphitoides $(\mathrm{LR}=0.382, P=$ $0.537)$ or $H$. fraxineus $(\mathrm{LR}=1.776, P=0.183)$.

Counts of spores collected on tape were made under a microscope. Spores $<10 \mu \mathrm{m}$ and those $>20 \mu \mathrm{m}$ were counted on tape recovered from nails and matches from the Maissin and Bievre sites over two different periods in 2014. For small spores, nails were more efficient than matches regardless of the site $(\mathrm{LR}=33.90, P<$ $0.0001)$. For large spores, the difference between nails and matches depended on the site (interaction of site $\times$ rod type: $L R=15.14, P<$ $0.0001)$. At Maissin, the nails captured more spores than the match rods, and in Bievre, the variation in spore counts was quite high, and there was no obvious difference between the two types of rods.

Optimization of the FungiSearch pipeline on MCs. The mean RA and HP were calculated for an MC of 10 fungal species (MC1, 100 pg DNA for each fungal species) and analyzed with three PCR primer sets and two HTS algorithms. There was no difference in taxonomic assignment between either algorithm except for Fusarium lateritium and Trametes versicolor (Table 3). The two groups of $F$. lateritum obtained with primer set 1 and the UPARSE algorithm corresponded to two sequences of variable lengths. There were no polymorphisms between the two sequences. Two groups of sequences were assigned to T. versicolor with primer set 2 and the UNOISE algorithm. They corresponded to two groups of $T$. versicolor ITS sequences in the reference database, differing by two polymorphisms in the region amplified with primer set 2 .

Based on the highest HP value, 10 fungal species were detected with primer set 2 , and only eight and seven species were assigned with primer sets 1 and 3, respectively. F. lateritium displayed an HP value of 1 with primer sets 1 and 3 and an HP value of 0.65 with primer set 2. Other fungal species including four Fusarium species were also detected, but their respective HP values were $<0.2$. $H$. fraxineus was not detected with primer sets 1 and 3 . With primer set $2(\mathrm{HP}=0.99)$, the percentage of reads was low compared with the other species of the MC regardless of the algorithm. Armillaria gallica was assigned with primer set $2(\mathrm{HP}=0.91)$, and it was assigned to a wrong species (Armillaria borealis) with primer sets 1 and 3. Ganoderma adspersum was assigned with primer sets 1 and 2 (HP >0.80), but it was less clear with primer set 3 (potential confusion with Ganoderma australe, HP $=0.50$ ). H. annosum, Verticillium dahliae, O. novo-ulmi, Eutypella caricae, and Nothophaeocryptopus gaeumannii had HP values $>0.80$ with all three primer sets (Table 3 ). Based on these preliminary results, primer set 2 was selected because it provided the highest specificity and sensitivity.

Although false positives were detected in the MC samples (RA ranging from 0.01 to $0.07 \%$ ), they were not detected in the negative controls (water).

The number of OTUs or ZOTUs generated with primer set 2 for the seven MCs of HTS run 1 was compared. BLAST analyses were conducted on the different sequences identified. A total of 48 OTUs

A HTS run 1

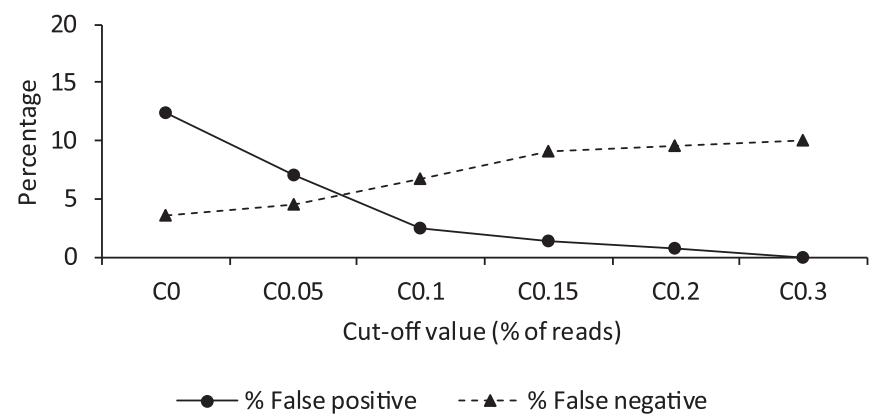

B

HTS run 2

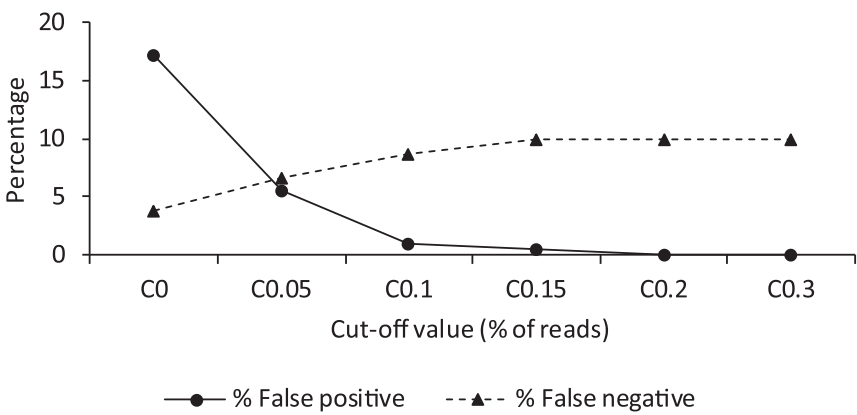

Fig. 3. Influence of a cutoff value of reads (from 0 to $0.3 \%$ of reads) on the proportion of false positives and false negatives in mock communities (MCs) of 10 fungi analyzed with primer set 2. A, Data from HTS run 1 (MC1 to MC7). B, Data from run 2 (MC2, MC3, MC4, MC5). Three HTS analyses for each cutoff value and two replicates for each mock community.

TABLE 3. Comparison between two high-throughput sequencing algorithms (UNOISE = ZOTU/UPARSE $=$ OTU) and three PCR primer sets (PS1, PS2, PS3) for the detection of 10 fungal species of a mock community (MC1, $100 \mathrm{pg}$ DNA/PCR for each fungal species, two replicates) ${ }^{\mathrm{a}}$

\begin{tabular}{|c|c|c|c|c|c|c|c|c|c|}
\hline \multirow[b]{3}{*}{ Species identified } & \multirow{2}{*}{\multicolumn{3}{|c|}{$\frac{\mathrm{HP}}{\mathrm{ZOTU} / \mathrm{OTU}}$}} & \multicolumn{6}{|c|}{ RA } \\
\hline & & & & \multicolumn{3}{|c|}{ ZOTU } & \multicolumn{3}{|c|}{ OTU } \\
\hline & PS1 & PS2 & PS3 & PS1 & PS2 & PS3 & PS1 & PS2 & PS3 \\
\hline Eutypella caricae (MC) & 1.00 & 1.00 & 1.00 & $3.9 \pm 0.1$ & $4.5 \pm 0.2$ & $2.7 \pm 0.0$ & $3.8 \pm 0.2$ & $4.3 \pm 0.0$ & $2.7 \pm 0.1$ \\
\hline Fusarium lateritium 1 (MC) & 1.00 & 0.65 & 1.00 & $13.7 \pm 0.2$ & $13.4 \pm 0.4$ & $13.8 \pm 0.3$ & $13.8 \pm 0.0$ & $13.6 \pm 0.3$ & $13.4 \pm 0.2$ \\
\hline Fusarium lateritium 2 (MC) & 0.59 & - & - & - & - & - & $0.07 \pm 0.1$ & - & - \\
\hline Heterobasidion annosum (MC) & 0.88 & 0.87 & 0.88 & $13.9 \pm 0.1$ & $10.7 \pm 0.1$ & $15.7 \pm 0.5$ & $14.4 \pm 0.1$ & $11.0 \pm 0.5$ & $15.5 \pm 1.1$ \\
\hline Hymenoscyphus fraxineus (MC) & - & 0.99 & - & - & $0.7 \pm 0.0$ & - & - & $0.8 \pm 0.0$ & - \\
\hline Nothophaeocryptopus gaeumannii (MC) & 1.00 & 1.00 & 1.00 & $8.1 \pm 0.4$ & $9.7 \pm 0.3$ & $6.3 \pm 0.2$ & $8.1 \pm 0.1$ & $9.2 \pm 0.1$ & $6.1 \pm 0.4$ \\
\hline Ophiostoma novo-ulmi (MC) & 0.96 & 0.94 & 1.00 & $8.3 \pm 0.2$ & $9.4 \pm 0.4$ & $7.6 \pm 0.4$ & $8.0 \pm 0.3$ & $9.4 \pm 0.2$ & $7.7 \pm 0.1$ \\
\hline Trametes versicolor 1 (MC) & 0.97 & 0.67 & 1.00 & $11.4 \pm 0.5$ & $8.6 \pm 0.2$ & $11.9 \pm 0.4$ & $11.7 \pm 0.1$ & $15.1 \pm 1.0$ & $12.0 \pm 0.2$ \\
\hline Trametes versicolor 2 (MC) & - & 0.80 & - & - & $6.3 \pm 0.1$ & - & - & - & - \\
\hline Verticillium dahliae (MC) & 0.96 & 0.97 & 0.93 & $21.5 \pm 1.6$ & $19.7 \pm 0.2$ & $20.5 \pm 0.3$ & $21.4 \pm 1.5$ & $19.8 \pm 0.0$ & $20.9 \pm 0.6$ \\
\hline
\end{tabular}

a No cutoff of reads, normalization set at 10,000 reads, percentage identity and coverage set at 99.5 and $85 \%$, respectively, data from HTS run 1. HP, hit proportion $(0-1)$; RA, read abundance (\%); NCAS = noncorrectly assigned species (indicated only in case of wrong taxonomic assignation or low HP value for the expected fungal species); dashes indicate no detection. 
were detected, among which 15 corresponded to contaminations (14 different fungal species, one species represented by two OTUs), nine did not correspond to any species, and 24 were correctly assigned sequences (the 10 species were detected). In contrast, only 19 ZOTUs were detected, among which four were contaminants (four different fungal species), one was a spurious sequence, and 14 corresponded to the 10 species of the MC. One species, $T$. versicolor, was represented by two sequences displaying single-nucleotide polymorphisms in two positions. Because the UNOISE algorithm was less prone to the creation of "spurious sequences" and allowed variation at the intraspecific level, it was selected for further analyses.

Cutoff of read proportion. The MCs from HTS run 1 (MC1A/ $\mathrm{B}$ to $\mathrm{MC} 7 \mathrm{~A} / \mathrm{B}, n=14)$ and $\mathrm{HTS}$ run $2(\mathrm{MC} 2 \mathrm{~A} / \mathrm{B}$ to $\mathrm{MC} 5 \mathrm{~A} / \mathrm{B}, n=8)$ screened with primer set 2 were analyzed with FungiSearch, considering all the reads (no cutoff) or limiting the reads to values above a threshold fixed at $0.05,0.1,0.15,0.2$, or $0.3 \%$ of reads (Fig. $3)$. Without any cutoff, $12.3 \%(19 / 154)$ and $17.2 \%(16 / 93)$ of species corresponding to contaminations were detected for HTS runs 1 and 2, respectively. When a cutoff of $0.05 \%$ of reads was applied, the percentage of false positives was $7.0 \%$ for run 1 and $5.5 \%$ for run 2 . All the reads corresponded to the 10 species of the MCs (no false positives) at a cutoff of $0.3 \%$ of reads for run 1 and at $0.2 \%$ of reads for run 2 . With no cutoff value applied, there were $3.6 \%(5 / 140)$ and $3.8 \%$ (3/80) false negative results. To limit the percentages of false positive and false negatives to their lowest level, a cutoff of $0.05 \%$ was applied to the reads of both runs (Fig. 3).

Limit of detection of the HTS method. The MCs from HTS run 1 were used to evaluate the limit of detection of the HTS method with primer set 2 and a cutoff of read abundance set at $0.05 \%$. All species were repeatedly detected at $10 \mathrm{pg} / \mathrm{MC}$ when they were in mixture with other species at $100 \mathrm{pg}$ (MC2 to MC4; Table 4). At $1 \mathrm{pg}$ per MC (MC5 to MC7), three species (A. gallica, E. caricae, and $H$. fraxineus) were not detected. Although the 10 species were used at the same concentration (100 pg) in MC1, the proportions of their reads were very different, with $V$. dahliae and $T$. versicolor being most represented (Table 4). Three nontarget species (Preussia minima, Sistotrema sernanderi, and Leptodontidium elatius) were also detected at RA values ranging from 0.03 to $0.16 \%$ (Table 4).

Repeatability and reproducibility of the HTS method. The RA of the 10 species analyzed with primer set 2 was compared between both replicates of MCs from the same HTS run (run 1) to evaluate the test repeatability (Fig. 4A). The comparison was also made between replicate 1 of MCs (MC2, MC3, MC4, and MC5) analyzed in HTS runs 1 and 2 to evaluate test reproducibility (Fig. 4B). The HTS method showed high Pearson correlation coefficients for repeatability $(r=0.998, P<0.001)$ and reproducibility $(r=$ $0.992, P<0.001)$. There was no significant effect of replicate (comparison of replicates A and B from HTS run $1, P=0.943$ ) or HTS run (comparison of replicate A from both HTS runs, $P=$ 0.986).

HTS analysis of forest samples. A selection of samples of DNA extracted from Rotorod samplers with nails that had been placed in the forest in 2014 (all five forest sites) and 2015 (only in Floriffoux) were analyzed via the FungiSearch pipeline. The number of reads per sample ranged from 19,629 to 55,491 for HTS run 1 and from 29,354 to 93,816 for HTS run 2. To work on a representative sample size for forest samples, the normalization level was set at 10,000 reads for run 1 and at 20,000 reads for run 2 after the rarefaction curves were analyzed (Supplementary Fig. S3).

An increment of the number of alignments retained for the BLAST analysis (max_target_seqs [MTS] option) from 20 to 1,000 increased the HP value until a stable value was reached for some species, including Alternaria tenuissima, C. cladosporioides, and Botrytis cinerea, because these species were represented by many sequences in the reference database, and the same E-value corresponded to different species from the same genus. Moreover, at the lowest value (MTS =20), the species Naevala minuissima (HP $=1$ ) was not detected in three samples. When these samples were analyzed with an MTS of 100 or 1,000, N. minuissima was detected at RAs ranging from 1.1 to $11.15 \%$.

On average, $32.4 \pm 9.9 \%$ of ZOTUs were assigned to fungal species. The number of species per sample ranged from 62 to 146 in HTS run 1 and from 51 to 155 in HTS run 2. The Simpson diversity index was $>0.8$ for all samples in run 1 , and three samples of run 2 had a lower diversity index.

The number of positive detections was determined for the specific qPCRs and the HTS method. For the interpretation of the data, the cutoff values were set at the $\mathrm{Ct}$ value at the limit of detection for real-time PCR and the cutoff of reads for the HTS method. The percentage of correct results ranged from $57 \%$ for E. alphitoides to $79 \%$ for $H$. annosum. The qPCR was more sensitive than the HTS method, especially for $H$. fraxineus, for which the diagnostic sensitivity of HTS was very low (26\%, 27 detections with the qPCR and seven detections with the HTS). The diagnostic specificity ranged from $71 \%$ for $H$. annosum to $100 \%$ for H. fraxineus (Table 5).

An analysis of the diversity of fungi collected in different forests was performed on HTS run 1. In total, 371 fungal species were detected, of which $47.2 \%$ belonged to the Ascomycota, $51.7 \%$ to the Basidiomycota (Fig. 5), $0.8 \%$ to the Zygomycota, and $0.3 \%$ to the Mucoromycota. Most species $(68.9 \%)$ had an HP value $=1,12.7 \%$

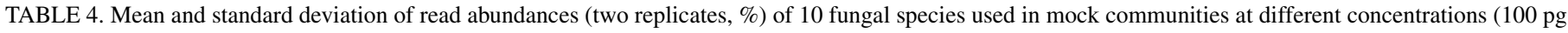
for $\mathrm{MC} 1,100 \mathrm{pg}$ and $10 \mathrm{pg}$ for MC2 to MC4, or $100 \mathrm{pg}$ and $1 \mathrm{pg}$ for MC5 to MC7) for high-throughput sequencing with primer set $2^{\mathrm{a}}$

\begin{tabular}{|c|c|c|c|c|c|c|c|}
\hline Species & $\mathrm{MC} 1$ & $\mathrm{MC} 2$ & MC3 & MC4 & MC5 & MC6 & MC7 \\
\hline Armillaria gallica & $5.57 \pm 0.21^{\mathrm{b}}$ & $5.48 \pm 0.06^{b}$ & $9.26 \pm 0.20^{\mathrm{b}}$ & $0.88 \pm 0.01^{\mathrm{c}}$ & $4.96 \pm 0.16^{\mathrm{b}}$ & $9.72 \pm 0.63^{b}$ & $0^{\mathrm{d}}$ \\
\hline Eutypella caricae & $4.44 \pm 0.19^{b}$ & $0.51 \pm 0.09^{c}$ & $11.14 \pm 0.59^{b}$ & $6.81 \pm 0.20^{\mathrm{b}}$ & $0^{\mathrm{d}}$ & $8.2 \pm 0.38^{b}$ & $6.21 \pm 0.18^{b}$ \\
\hline Fusarium lateritium & $13.85 \pm 0.43^{b}$ & $19.54 \pm 0.99^{b}$ & $5.07 \pm 0.44^{\mathrm{c}}$ & $18.62 \pm 0.78^{b}$ & $19.17 \pm 0.22^{b}$ & $0.70 \pm 0.07^{\mathrm{d}}$ & $20.22 \pm 0.03^{\mathrm{b}}$ \\
\hline Ganoderma adspersum & $11.85 \pm 0.14^{\mathrm{b}}$ & $11.97 \pm 0.64^{\mathrm{b}}$ & $3.38 \pm 0.05^{\mathrm{c}}$ & $13.98 \pm 0.17^{\mathrm{b}}$ & $11.81 \pm 0.50^{\mathrm{b}}$ & $0.42 \pm 0.05^{\mathrm{d}}$ & $14.06 \pm 0.66^{\mathrm{b}}$ \\
\hline Heterobasidion annosum & $10.99 \pm 0.39^{b}$ & $9.94 \pm 1.02^{b}$ & $17.24 \pm 0.16^{\mathrm{b}}$ & $1.69 \pm 0.13^{c}$ & $9.58 \pm 0.65^{b}$ & $22.23 \pm 0.42^{b}$ & $0.09 \pm 0.01^{\mathrm{d}}$ \\
\hline Hymenoscyphus fraxineus & $0.71 \pm 0.12^{\mathrm{b}}$ & $0.1 \pm 0.03^{c}$ & $1.48 \pm 0.06^{\mathrm{b}}$ & $0.79 \pm 0.13^{b}$ & $0^{\mathrm{d}}$ & $2.03 \pm 0.06^{\mathrm{b}}$ & $0.71 \pm 0.02^{\mathrm{b}}$ \\
\hline Nothophaeocryptopus gaeumannii & $9.11 \pm 0.01^{\mathrm{b}}$ & $1.22 \pm 0.10^{\mathrm{c}}$ & $20.11 \pm 0.34^{\mathrm{b}}$ & $12.49 \pm 0.27^{\mathrm{b}}$ & $0.12 \pm 0.06^{\mathrm{d}}$ & $28.48 \pm 0.09^{\mathrm{b}}$ & $12.37 \pm 0.57^{\mathrm{b}}$ \\
\hline Ophiostoma novo-ulmi & $9.32 \pm 0.03^{\mathrm{b}}$ & $12.48 \pm 0.33^{\mathrm{b}}$ & $19.21 \pm 0.14^{\mathrm{b}}$ & $2.08 \pm 0.01^{\mathrm{c}}$ & $12.25 \pm 1.60^{\mathrm{b}}$ & $25.99 \pm 0.40^{\mathrm{b}}$ & $0.17 \pm 0.02^{\mathrm{C}}$ \\
\hline Trametes versicolor & $14.63 \pm 0.08^{b}$ & $16.55 \pm 0.35^{\mathrm{b}}$ & $5.12 \pm 0.20^{\mathrm{c}}$ & $19.33 \pm 0.81^{\mathrm{b}}$ & $20.1 \pm 1.13^{b}$ & $0.74 \pm 0.08^{d}$ & $21.99 \pm 0.77^{\mathrm{b}}$ \\
\hline Verticillium dahliae & $19.68 \pm 0.73^{b}$ & $22.17 \pm 0.11^{\mathrm{b}}$ & $7.82 \pm 0.18^{\mathrm{c}}$ & $23.31 \pm 0.33^{\mathrm{b}}$ & $21.93 \pm 0.90^{\mathrm{b}}$ & $1.29 \pm 0.11^{\mathrm{d}}$ & $24.14 \pm 0.27^{\mathrm{b}}$ \\
\hline Preussia minima $(\mathrm{Co})$ & $0.03 \pm 0.04$ & 0 & 0 & 0 & 0 & 0 & 0 \\
\hline Sistotrema sernanderi (Co) & $0.04 \pm 0.06$ & 0 & $0.10 \pm 0.03$ & 0 & $0.05 \pm 0.07$ & $0.16 \pm 0.08$ & 0 \\
\hline Leptodontidium elatius (Co) & 0 & 0 & 0 & 0 & 0 & $0.05 \pm 0.07$ & 0 \\
\hline
\end{tabular}

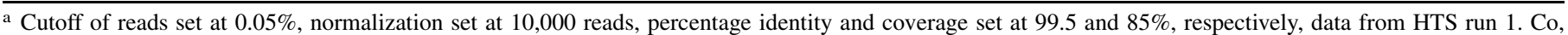
contaminant species.

b DNA used at $100 \mathrm{pg} / \mathrm{PCR}$

c DNA used at $10 \mathrm{pg} / \mathrm{PCR}$.

d DNA used at $1 \mathrm{pg} / \mathrm{PCR}$. 
an HP value between 0.75 and $0.99 \%$, and $18.4 \%$ had an HP value $<0.75$. For 63 species (18 Ascomycota, 43 Basidiomycota, and two Zygomycota), multiple ZOTUs (two to five per species) were identified. Most of these ZOTUs were identified in at least two samples or were $100 \%$ identical to accession numbers in the reference database.

A heat map and hierarchical clustering of HTS results from runs 1 and 2 highlighted four groups of samples (group A to D) apparently reflecting the season of the year (Supplementary Fig. S4). Indeed, in Floriffoux (mixed forest), where spore collections were regularly conducted in 2014 and 2015, group C included the earliest capture dates (May to June 2014 and June to July 2015), groups A and D included the intermediate capture dates (June to September 2014 and July to August 2015), and group B included the latest capture dates (September to October 2014 and September 2015). The sites with low tree species diversity (Maissin, Bievre, Morialme, and Carlsbourg) were spread over all the sample clusters. HTS runs did not cluster differently, whereas samples from the same site and the same collection period (two different traps) were very close to each other in the dendrogram. Different groups of fungal species (groups 1 to 4) were also identified, with some groups being present in most sample clusters, whereas others were present mostly in one sample cluster. As an example, some species from species group 2 were present mainly in sample group B, corresponding to samples collected in autumn. In contrast, some species from cluster 4 were present in all sample groups, suggesting that spores from these species are produced in all seasons.

A large number of fungal pathogens were detected, with most of them being forest pathogens (e.g., Apiognomonia errabunda, Bjerkandera adusta, Fomes fomentarius, Fomitopsis pinicola, Gymnopus fusipes, Laetiporus sulphureus, Lophodermium piceae, Melampsora laricis-populina, Meria laricis, Nothophaeocryptopus gaeumannii, Taphrina carpini, and Trametes versicolor). Fungal pathogens of cultivated plants, notably Blumeria graminis, Claviceps purpurea, Microdochium nivale, Fusarium graminearum, Sclerotinia sclerotiorum, and Ustilago striiformis, were also detected.

The EPPO alert system was triggered in four cases. In three of the cases, the HP values (Alternaria mali, $\mathrm{HP}=0.03$; Heterobasidion irregulare, $\mathrm{HP}=0.06$; and Verticillium dahliae, $\mathrm{HP}=0.03$ ) meant a false alert could be concluded. In the remaining case, analysis of the BLAST file revealed that 23 sequences were assigned to two fungal species, Tilletia indica (HP $=0.61$, a regulated pathogen) and T. walkeri $(\mathrm{HP}=0.39$, a nonregulated pathogen $)$. Both species had
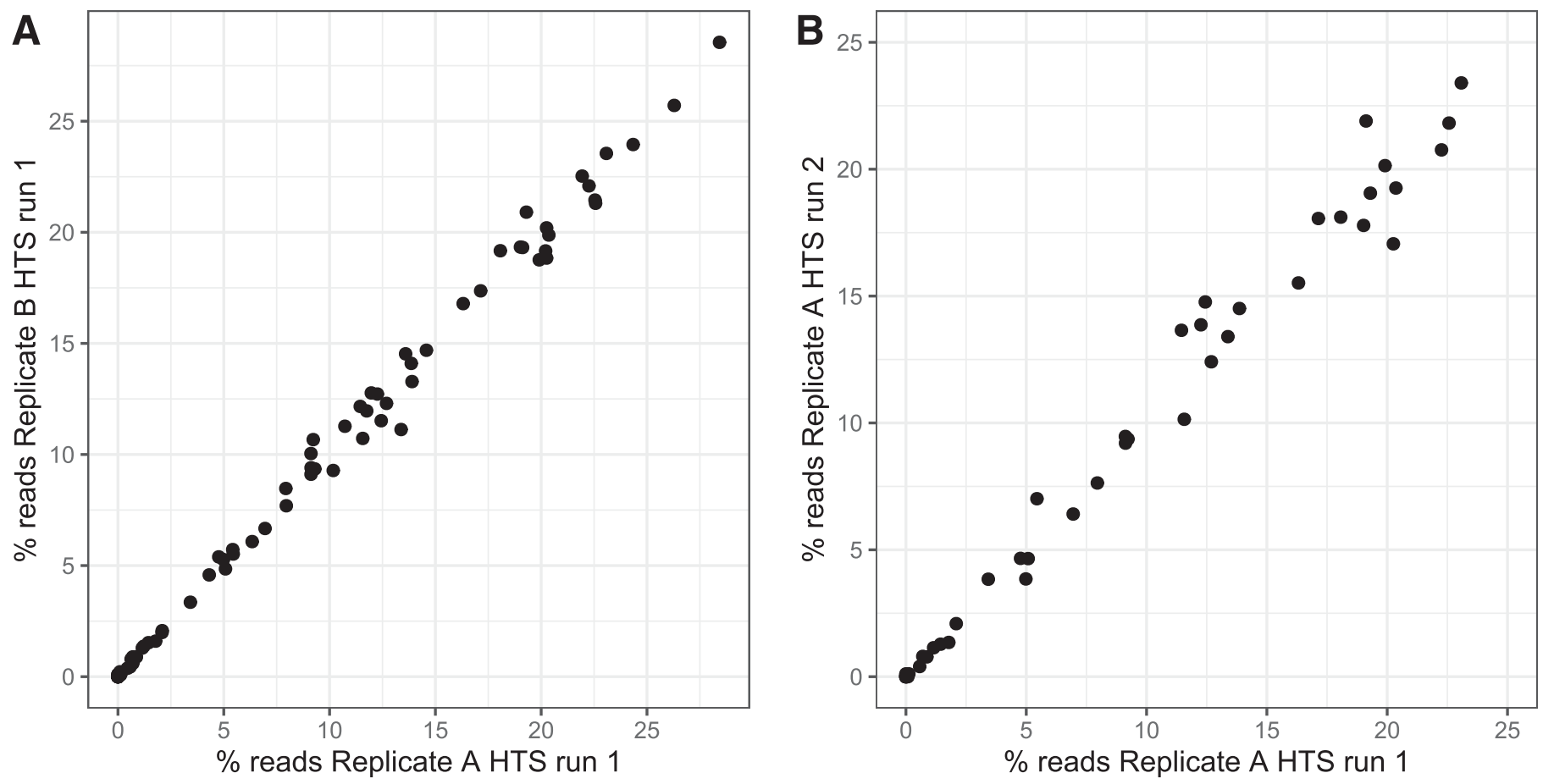

Fig. 4. A, Repeatability (read abundance (\%) in two replicates of the seven mock communities [MCs] of HTS run 1) and B, Reproducibility (read abundance [\%] in replicate A of the mock communities MC2, MC3, MC4, and MC5 tested in HTS run 1 and HTS run 2) of HTS method with primer set 2. Normalization at 10,000 reads for run 1 and at 20,000 reads for run 2, reads cutoff at $0.05 \%$, BLAST analysis with a percentage identity and a query coverage set at 99.5 and $85 \%$, respectively.

TABLE 5. Comparison between high-throughput sequencing (HTS) and quantitative PCR (qPCR) for the detection of three pathogenic fungi in 47 forest samples ${ }^{\mathrm{a}}$

\begin{tabular}{lccr}
\hline Diagnostic results & Heterobasidion annosum & Erysiphe alphitoides & Hymenoscyphus fraxineus \\
\hline Positive with HTS and qPCR & 32 & 13 & 7 \\
Negative with HTS and qPCR & 5 & 14 & 20 \\
Positive with HTS and negative with qPCR & 2 & 3 & 0 \\
Negative with HTS and positive with qPCR & 8 & 17 & 20 \\
Total & 47 & 47 & 47 \\
Diagnostic sensitivity (\%) & 80 & 43 & 26 \\
Diagnostic specificity (\%) & 71 & 82 & 100 \\
Correct results (\%) & 79 & 57 & 57
\end{tabular}

${ }^{a}$ For HTS analysis, cutoff at $0.05 \%$ reads, normalization at 10,000 reads for run 1 and 20,000 reads for run 2, percentage identity and coverage at 99.5 and $85 \%$, respectively. For qPCR, fluorescence threshold set at 0.2 (StepOne Plus device), cutoff based on standard curves. 
the same E-value. The T. indica barcode was identified in one location, on one date in one replicate.

\section{DISCUSSION}

Spore trapping. To detect emerging fungal diseases, it is essential to use spore traps capable of collecting a broad spectrum of fungal pathogens. Because some species produce an airborne inoculum and others a rainborne inoculum, both air and rain samplers should be used in combination, as demonstrated by Chen et al. (2018). Although the Burkard sampler has proven to be reliable and accurate for monitoring of airborne spores for epidemiological studies dealing with agricultural crops (Duvivier et al. 2013; Wieczorek et al. 2014), it is not suited to diagnostic purposes in the forest environment because it is too bulky and too heavy to be transported to remote forest areas that can be inaccessible to motorized vehicles. In addition, because of its high cost, it is not affordable to be deployed on a large scale for phytosanitary surveillance. Using Vaseline on the Melinex tape of the Burkard and cutting the coated Melinex tape into segments for DNA extraction is not suited to routine testing and is a process that might lead to contamination if handling is not performed aseptically (in a laminar flow hood). Portable Rotorod samplers, being lighter and less expensive, are more suited to phytosanitary surveillance in a forest situation because several can be inexpensively deployed over a large area (Quesada et al. 2018). Moreover, the use of selfadhesive tape makes the device easy to manipulate by nonskilled operators with a low risk of contamination because the impaction surface is made accessible to the spores at the moment of collection in the forest. The rods are also easily removed from the Rotorod and placed directly into plastic tubes in the forest for postsampling analyses, thereby avoiding risk of contamination. The need to replace the devices frequently is the main disadvantage of Rotorod samplers. Using timers to activate the Rotorods at specific times of

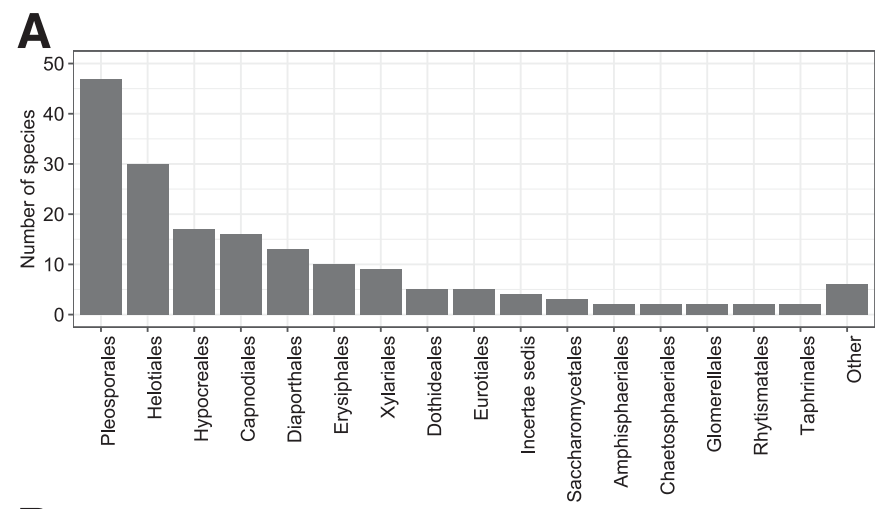

B

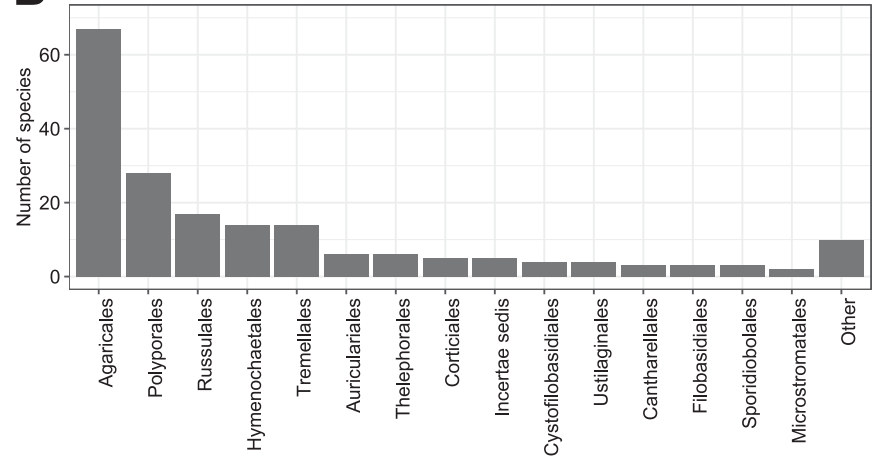

Fig. 5. Distribution of the different fungal orders identified in HTS run 1 (four sampling periods in the mixed forest and 1 sampling period in each of the lowdiversity forests in 2014). The listed orders were those with $\geq 2$ species. A, Division Ascomycota. B, Division Basidiomycota. day could ensure the most appropriate collection period. However, the sampling period of the Rotorod is limited because nontarget material (notably pollen and dust) can overload the impaction surface, decreasing the spore collection efficiency (Aylor 1993).

Two types of rods with an equal impaction surface (double-sided tape) but a different width (the nail was narrower than match) were not equivalent for the collection of small spores $(<10 \mu \mathrm{m})$, with nails being more efficient. This observation is in agreement with other studies showing that rod width influences collection efficiency (McCartney et al. 1997), with narrow collection surfaces being more appropriate for collecting small spores (Edmonds 1972).

Spore release pattern and specific $q$ PCR. The pattern of spore dispersal determined from spores collected by the Burkard sampler via specific qPCRs was in agreement with data reported from other European countries (Gonthier et al. 2005; Grosdidier et al. 2018; Marçais et al. 2009). The qPCR tests used, including the test developed in this study for the detection of E. alphitoides, were therefore adapted to the specific quantification of the three pathogens.

The new tool, FungiSearch. Several bioinformatic pipelines are available for the analysis of HTS datasets (Anslan et al. 2018). However, these tools have been designed for analysis of fungal communities rather than detection of fungal species. Moreover, they are linked to a reference database, generally to UNITE for fungi (Abarenkov et al. 2010), that cannot be updated easily by the operator. In this context, a new HTS pipeline has been developed. The pipeline, FungiSearch, operates on a regular computer, allows the diagnostician to work in the Windows environment, and can be used by people who are not skilled in bioinformatics. The reference database can be updated, which is a significant advantage in biosurveillance, where new threats can arise at any time, and where it is necessary to reanalyze previous data based on new accessions available in the reference database.

Parameters for HTS analysis. Based on the highest HP value for the most probable species identification, the primer set targeting ITS2 was most able to detect the 10 species in the MC. The remaining two primer sets targeting ITS1 failed to detect some species (low sensitivity) or detected species that were not in the MCs (low specificity). The results are in agreement with other studies indicating that ITS2 is more suitable than ITS1 for fungal metabarcoding (Lindahl et al. 2013; Tedersoo et al. 2015; Yang et al. 2018).

Spurious sequences can result from errors in PCR. Occasionally, nucleotide substitutions or artificial hybridization of DNA fragments belonging to different clones may occur, creating chimeras. Also, contaminants in the PCR reaction from the laboratory environment can lead to misinterpretation of HTS results. Based on the two algorithms implemented in USEARCH (UPARSE and UNOISE), 19\% of the OTUs could not be assigned correctly by UPARSE, and one ZOTU could not be assigned correctly by UNOISE. In addition, the number of sequences corresponding to contaminants was lower in UNOISE (21\%) compared with UPARSE (31\%), suggesting that UNOISE with the parameters tested in this study gave superior filtration of reads and reduced misinterpretation of the data.

With regard to contaminants, our data demonstrate that negative controls of water alone were not suitable for the HTS procedure we used, because the number of reads in these samples was too low for the clustering algorithm to operate. In contrast, using DNA from MCs of fungal species provided useful positive and negative controls. Therefore, using MCs in each HTS run is highly recommended. False positives were repeatedly detected in the 22 MCs in run 1 and 2. To limit contaminants, low-abundance reads were removed according to a selectable threshold. In our study, it was set at $0.05 \%$ of reads.

Interpretation of results from FungiSearch. The HTS method we developed made it possible to identify taxa to the species level. The high level of specificity is essential for the surveillance of 
invasive or regulated pathogens because some diseases can be caused by cryptic fungal species that are sometimes difficult to distinguish (Ghelardini et al. 2016). Moreover, the UNOISE algorithm made possible the identification of variable ITS sequences (i.e., different ZOTUs) in 63 fungal species identified in the forest samples. These promising results also must be considered. First, the existence of intraspecific variation of ITS copies has been demonstrated in fungi (Woo et al. 2010; Zhao et al. 2015), and identifying this feature is of great interest for phylogenetic studies. Second, the maximum number of hits selected by BLAST for the analysis (MTS value) proved to be crucial for the correct taxonomic assignment of species with a very large number of accessions. Given the increasing number of sequences available on public databases, it is strongly recommended to verify that the MTS value is above the total number of accessions for each species identified. If this is not the case, the analysis should be restarted after increments to the MTS value. Third, there are situations where species cannot be discriminated on the basis of the amplified region (ITS2 in our study). In one forest sample, the species T. indica was detected with an HP value of 0.61, suggesting that it could be present in the sample. Because this fungus is a quarantine pathogen in Europe, the result was questionable. Based on the information provided by the pipeline, the other probable species was T. walkeri, a nonregulated pathogen that had an HP value of 0.39. Levy et al. (2001) demonstrated that the two Tilletia species had the same ITS2 region sequence. This result highlights the need to analyze the data carefully, especially the HP values of the different species proposed by the pipeline. In this case, only two species were proposed, with similar HP values (several accessions for each species were proposed), suggesting a problem in discriminating between the two species. Fourth, situations occur where species are incorrectly assigned because of errors in the reference database. If an accession of species A is incorrectly assigned to species B, two outcomes may arise: Either species B is represented by a large number of accessions in the reference database, in which case the HP value allows the selection of the correct species (species B), or species B is represented by a small number of accessions, or even a single accession (perhaps in the case of a new species), in which case the HP value will be similar for both species, but the number of accessions for both species will also be low. This last situation shows that besides the HP value, the total number of accessions in the reference database is an important parameter to consider when interpreting the results. Fifth, a species may have undergone taxonomic reclassification so the name has changed. For instance, Phaeocryptopus gaeumannii is now named Nothophaeocryptopus gaeumannii (Videira et al. 2017); Chalara fraxinea, causing ash dieback (Kowalski 2006), was first reclassified as Hymenoscyphus pseudoalbidus (Gross et al. 2014) but is now classified as H. fraxineus (Baral and Bremmann 2014). The use of the HP parameter and a reference database where the reference sequences are sorted by release date, considering the most recent sequences first, limit the risk of using a defunct taxonomic moniker.

The HTS method was less sensitive than qPCR. These results contrast with those of Tremblay et al. (2018). The difference could be explained by the PCR primers used or the number of PCR cycles used. An increase in the number of PCR cycles could increase the sensitivity of the HTS method. However, this could also increase the risk of false positives and promote the detection of abundant species over rare species. Most often, species such as Cladosporium spp. or Epicoccum nigrum were the dominant species found in the samples in this study. Their high abundance might mask the presence of rare species. An increase in the depth of reads could partly solve the problem, but current techniques have their limits. Enrichment or filtration protocols, allowing the removal of nontarget species, could alleviate this sensitivity issue. Enrichment strategies have been described, particularly in HTS techniques dedicated to virus (Paskey et al. 2019) or GMO (Debode et al. 2019) detection. The HTS method was not efficient for the detection of $H$. fraxineus.
Because the amplicon size generated with primer set 2 was compatible with the MiSeq pair-ended technology, one explanation might be the existence of secondary structures in the amplicon sequence impairing the hybridization process in the flow cell.

Collecting and identifying forest airborne fungal communities. The method we developed highlighted the great diversity of fungal species present in the atmosphere in temperate forests, with up to 155 species collected within 2 days of sampling per trap. The proportion of Ascomycota and Basidiomycota was similar, demonstrating that the tool combining spore trapping with Rotorod samplers and HTS analysis by using the FungiSearch pipeline is well adapted to the surveillance of a wide range of fungal pathogens. The analysis also revealed the influence of the season on the diversity of spores collected on traps, with a greater diversity at the end of the growing season. Finally, pathogens were more common in forests where their hosts were dominant, thereby reinforcing the interest of mixed forests to buffer the impact of fungal diseases caused by native pathogens or pathogens that were introduced a long time ago.

Conclusion. A procedure combining spore trapping with Rotorod samplers, amplicon sequencing, and bioinformatic analysis of the data with the FungiSearch pipeline has been evaluated for the detection of airborne inoculum of forest fungal species. Although less sensitive than qPCR, the HTS technique shows great potential as a new diagnostic method. Its capacity to detect a broad spectrum of fungal species belonging to the Ascomycota and Basidiomycota makes it usable in other environments, notably in agricultural fields, fruit orchards, and greenhouses. It is also applicable to the detection of other organisms if the reference database and the PCR primers are adapted to the targeted group. Finally, the ability of FungiSearch to identify microorganisms at the species level makes it a promising tool for characterizing the role of the phytobiome in disease development. However, the expertise of the diagnostician remains essential for translating sequence data to the correct fungal species ID. In addition, the future of HTS diagnostics might require a community effort by mycologists and diagnosticians to create a curated database as complete as possible and properly maintained and to identify any blind zones for each protocol to ensure a maximum taxonomic resolution and the inclusiveness of an HTS diagnostic test.

\section{ACKNOWLEDGMENTS}

We thank Béatrice Henricot for critical review of the manuscript, Quentin Ledoux (CRAW) for the experiments dealing with microscopic observations of spores; Mathilde Eck (Liege University Gembloux, Agro-Bio Tech) for the provision of raw sequencing data on NCBI; and Mélanie Gourgue, Fabien Gisher, and Martin Helson for technical assistance in collecting spores in the forests and analyzing the samples.

\section{LITERATURE CITED}

Abarenkov, K., Nilsson, H. R., Larsson, K. H., Alexander, I. J., Eberhardt, U., Erland, S., Høiland, K., Kjøller, R., Larsson, E., Pennanen, T., Sen, R., Taylor, A. F., Tedersoo, L., Ursing, B. M., Vrålstad, T., Liimatainen, K., Peintner, U., and Kõljalg, U. 2010. The UNITE database for molecular identification of fungi - recent updates and future perspectives. New Phytol. 186:281-285.

Aguayo, J., Fourrier-Jeandel, C., Husson, C., and Ioos, R. 2018. Assessment of passive spore traps combined with high-throughput sequencing to study airborne fungal communities. Appl. Environ. Microbiol. 84:e02637-17.

Allen, E. A., and Humble, L. 2002. Non-indigenous species introductions: a threat to Canada's forests and forest economy. Can. J. Plant Pathol. 24: 103-110.

Anslan, S., Nilsson, H., Wurzbacher, C., Baldrian, P., Tedersoo, L., and Bahram, M. 2018. Great differences in performance and outcome of highthroughput sequencing data analysis platforms for fungal metabarcoding. MycoKeys 39:29-40.

Aylor, D. E. 1993. Relative collection efficiency of Rotorod and Burkard spore samplers for airborne Venturia inaequalis ascospores. Phytopathology 83: 1116-1119. 
Banchi, E., Gennaro Ametrano, C., Stanković, D., Verardo, P., Moretti, O., Gabrielli, F., Lazzarin, S., Borney, M. F., Tassan, F., Tretiach, M., Pallavicini, M., and Muggia, L. 2018. DNA metabarcoding uncovers fungal diversity of mixed airborne samples in Italy. PLoS One 13: e0194489.

Banchi, E., Pallavicini, A., and Muggia, L. 2019. Relevance of plant and fungal DNA metabarcoding in aerobiology. Aerobiologia 36:9-23.

Baral, H. O., and Bremmann, M. 2014. Hymenoscyphus fraxineus vs. Hymenoscyphus albidus: a comparative light microscopic study on the causal agent of European ash dieback and related foliicolous, stroma-forming species. Mycology 5:228-290.

Bates, D., Mächler, M., Bolker, B., and Walker, S. 2015. Fitting linear mixedeffects models using lme4. J. Stat. Softw. 67:1-48.

Bensch, K., Groenewald, J. Z., Braun, U., Dijksterhuis, J., de Jesus Yañez-Morales, M., and Crous, P. W. 2015. Common but different: the expanding realm of Cladosporium. Stud. Mycol. 82:23-74.

Bérubé, J. A., Gagné, P. N., Ponchart, J. P., Tremblay, E. D., and Bilodeau, G. 2018. Detection of Diplodia corticola spores in Ontario and Québec based on high throughput sequencing (HTS) methods. Can. J. Plant Pathol. 40: 378-386.

Blackwell, M. 2011. The fungi 1,2,3... 5.1 million species? Am. J. Bot. 98: 426-438.

Bodles, W. A., Fossdal, C. G., and Woodward, S. 2006. Multiplex real-time PCR detection of pathogen colonization in the bark and wood of Picea sitchensis clones differing in resistance to Heterobasidion annosum. Tree Physiol. 26:775-782.

Brasier, C. M. 1991. Ophiostoma novo-ulmi sp. nov., causative agent of current Dutch elm disease pandemics. Mycopathologia 115:151-161.

Brown, J., and Hovmøller, M. S. 2002. Aerial dispersal of pathogens on the global and continental scales and its impact on plant disease. Science 297: 537-541.

Calderon, C., Ward, E., Freeman, J., and McCartney, A. 2002. Detection of airborne fungal spores sampled by rotating-arm and Hirst-type spore traps using polymerase chain reaction. J. Aerosol Sci. 33:283-296.

Chandelier, A., André, F., and Laurent, F. 2010. Detection of Chalara fraxinea in common ash (Fraxinus excelsior) using real time PCR. For. Pathol. 40: $87-95$.

Chandelier, A., Helson, M., Dvorak, M., and Gischer, F. 2014. Detection and quantification of airborne inoculum of Hymenoscyphus pseudoalbidus using real-time PCR assays. Plant Pathol. 63:1296-1305.

Chen, G., and Meentemeyer, R. K. 2016. Remote sensing of forest damage by diseases and insects. Pages 145-162 in: Remote Sensing for Sustainability. Q. Weng, ed. CRC Press, Boca Raton, FL.

Chen, W., Hambleton, S., Sufert, K. A., Carisse, O., Diarra, M. S., Peters, R. D., Lowe, C., Chapados, T. T., and Levesque, C. A. 2018. Assessing performance of spore samplers in monitoring aeromycobiota and fungal plant pathogen diversity in Canada. Appl. Environ. Microbiol. 84:e0260117.

Chornesky, E. A., Bartuska, A. M., Aplet, G. H., Britton, K. O., Cummings-Carlson, J., Davis, F. W., Eskow, J., Gordon, D. R., Gottschalk, K. W., Haack, R. A., Hansen, A. J., Mack, R. N., Rahel, F. J., Shannon, M. A., Wainger, L. A., and Wigley, T. B. 2005. Science priorities for reducing the threat of invasive species to sustainable forestry. Bioscience 55:335-348.

Crocker, E., Condon, B., Almsaeed, A., Jarret, B., Dana Nelson, C., Abbott, A. G., Main, D., and Staton, M. 2020. TreeSnap: A citizen science app connecting tree enthusiasts and forest scientists. Plants People Planet 2: 47-52.

Debode, F., Hulin, J., Charloteaux, B., Coppieters, W., Hanikenne, M., Karim, L., and Berben, G. 2019. Detection and identification of transgenic events by next generation sequencing combined with enrichment technologies. Sci. Rep. 9:15595.

Drenkhan, R., Solheim, H., Bogacheva, A., Riit, T., Adamson, K., Drenkhan, T., Maaten, T., and Hietala, A. M. 2017. Hymenoscyphus fraxineus is a leaf pathogen of local Fraxinus species in the Russian Far East. Plant Pathol. 66: 490-500.

Duvivier, M., Dedeurwaerder, G., De Proft, M., Moreau, J. M., and Legrève, A. 2013. Real-time PCR quantification and spatio-temporal distribution of airborne inoculum of Mycosphaerella graminicola in Belgium. Eur. J. Plant Pathol. 137:325-341.

Dvořák, M., Janoš, P., Botella, L., Rotkova, G., and Zas, R. 2017. Spore dispersal patterns of Fusarium circinatum on an infested Montery Pine forest in North-Western Spain. Forests 8:432.

Edgar, R. C. 2010. Search and clustering orders of magnitude faster than BLAST. Bioinformatics 26:2460-2461.

Edgar, R. C. 2013. UPARSE; Highly accurate OTU sequences from microbial amplicon reads. Nat. Methods 10:996-998.

Edgar, R. C. 2016. UNOISE2: improved error-correction for Illumina $16 \mathrm{~S}$ and ITS amplicon sequencing. bioRxiv 081257.
Edgar, R. C., and Flyvbjerg, H. 2015. Error filtering, pair assembly and error correction for next-generation sequencing reads. Bioinformatics 31: 3476-3482.

Edmonds, R. L. 1972. Collection efficiency of Rotorod samplers for sampling fungus spores in the atmosphere. Plant Dis. Rep. 56:704-708.

EPPO. 2018. PM7/76(5) - Use of EPPO Diagnostic standards. OEPP EPPO Bull 48:373-377.

Gardes, M., and Bruns, T. D. 1993. ITS primers with enhanced specificity for basidiomycetes - application to the identification of mycorrhizae and rusts. Mol. Ecol. 2:113-118

Ghelardini, L., Pepori, A. L., Luchi, N., Capretti, P., and Santini, A. 2016. Drivers of emerging fungal diseases of forest trees. For. Ecol. Manage. 381: 235-246.

Gonthier, P., Garbelotto, M. M., and Nicoletti, G. 2005. Seasonal patterns of spore deposition of Heterobasidion species in four forests of the Western Alps. Phytopathology 95:759-767.

Grosdidier, M., Ioos, R., Husson, C., Cael, O., Scordia, T., and Marçais, B. 2018. Tracking the invasion: dispersal of Hymenoscyphus fraxineus airborne inoculum at different scales. FEMS Microbiol. Ecol. 94: fiy049.

Gross, A., Holdenrieder, O., Pautasso, M., Queloz, V., and Sieber, T. N. 2014. Hymenoscyphus pseudoalbidus, the causal agent of European ash dieback. Mol. Plant Pathol. 15:5-21.

Jackson, S. L., and Bayliss, K. L. 2011. Spore traps need improvements to fulfil plant biosecurity requirements. Plant Pathol. 60:801-810.

Klapwijk, M. J., Hopkins, A. J. M., Eriksson, L., Pettersson, M., Schroeder, M., Lindelöw, A., Rönnberg, J., Keskitalo, E. C. H., and Kenis, M. 2016. Reducing the risk of invasive forest pests and pathogens: combining legislation, targeted management and public awareness. Ambio:223-234.

Kowalski, T. 2006. Chalara fraxinea sp. nov. associated with dieback of ash (Fraxinus excelsior) in Poland. For. Pathol. 36:264-270.

Levy, L., Castlebury, L. A., Carris, L. M., Meyer, R. J., and Pimentel, G. 2001. Internal transcribed spacer sequence-based phylogeny and polymerase chain reaction-restriction fragment Length polymorphism differentiation of Tilletia walkeri and T. indica. Phytopathology 91:935-940.

Lindahl, B. D., Nilsson, R. H., Tedersoo, L., Abarenkov, K., Carlsen, T., Kjøller, R., Kõljalg, U., Pennanen, T., Rosendahl, S., Stenlid, J., and Kauserud, H. 2013. Fungal community analysis by high throughput sequencing of amplified markers: a user's guide. New Phytol. 199:288-299.

Lovett, G. M., Canham, C. D., Arthur, M. A., Weathers, K. C., and Fitzhugh, R. D. 2006. Forest ecosystem responses to exotic pests and pathogens in eastern North America. Bioscience 56:395-405.

Marçais, B., Kavkova, M., and Deprez-Loustau, M. L. 2009. Phenotypic variation in the phenology of ascospore production between European populations of oak powdery mildew. Ann. Sci. 66:814-822.

Marçais, B., Piou, D., Dezette, D., and Desprez-Loustau, M. L. 2017. Can oak powdery mildew severity be explained by indirect effects of climate on the composition of the Erysiphe pathogenic complex? Phytopathology 107: 570-579.

Martin, R. R., Constable, F., and Tzanetakis, I. E. 2016. Quarantine regulations and the impact of modern detection methods. Annu. Rev. Phytopathol. 54: 189-205.

Massart, S., Olmos, O., Jijakli, H., and Candresse, T. 2014. Current impact and future directions of high throughput sequencing in plant virus diagnostics. Virus Res. 188:90-96.

McCartney, H. A., Fitt, B. D. L., and Schmechel, D. 1997. Sampling bioaerosols in plant pathology. J. Aerosol Sci. 28:349-364.

Nilsson, R. H., Anslan, S., Bahram, M., Wurzbacher, C., Baldrian, P., and Tedersoo, L. 2019. Mycobiome diversity: high-throughput sequencing and identification of fungi. Nat. Rev. Microbiol. 17:95-109.

Oksanen, J., Blanchet, F. G., Friendly, M., Kindt, R., Legendre, P., McGlinn, D., Minchin, P. R., O'Hara, R. B., Simpson, G. L., Solymos, P., Stevens, M. H. H., Szoecs, E., and Wagner, H. 2019. vegan: Community Ecology Package. $\mathrm{R}$ package version 2.5-6. https://CRAN.R-project.org/ package $=$ vegan

Olmos, A., Boonham, N., Candresse, T., Gentit, P., Giovani, B., Kutnjak, D., Liefting, L., Maree, H. J., Minafra, A., Moreira, A., Nakhla, M. K., Petter, F., Ravnikar, M., Rodoni, B., Roenhorst, J. W., Rott, M., Ruiz-Garcı, A. B., Santala, J., Stancanelli, G., van der Vlugt, R., Varveri, C., Westenberg, M., Wetzel, T., Ziebell, H., and Massart, S. 2018. High-throughput sequencing technologies for plant pest diagnosis: challenges and opportunities. OEPP EPPO Bull 48:219-224.

Oluseyi Osunmakinde, C., Selvarajan, R., Mamba, B. B. and Msagati, T. A. M. 2019. Profiling bacterial diversity and potential pathogens in wastewater treatment plants using high-throughput sequencing analysis. Microorganisms 7:506.

Paskey, A. C., Frey, K. G., Schroth, G., Gross, S., Hamilton, T., and Bishop-Lilly, K. A. 2019. Enrichment post-library preparation enhances the sensitivity of high-throughput sequencing-based detection and characterization of viruses from complex samples. BMC Genomics 20:155. 
Purahong, W., Pietsch, K. A., Bruelheide, H., Wirth, C., Buscot, F., and Wubet, T. 2019. Potential links between wood-inhabiting and soil fungal communities: evidence from high throughput sequencing. MicrobiologyOpen 8: e00856.

Quesada, T., Hughes, J., Smith, K., Shin, K., James, P., and Smith, J. 2018. A low-cost spore trap allows collection and real-time PCR quantification of airborne Fusarium circinatum. Forests 9:586.

R Core Team. 2019. R: A Language and Environment for Statistical Computing. R Foundation for Statistical Computing, Vienna, Austria. http:// www.R-project.org/

Ramsfield, T. D., Bentz, B. J., Faccoli, M., Jactel, H., and Brockerhoff, E. G. 2016. Forest health in a changing world: effects of globalization and climate change on forest insect and pathogen impact. Forestry. Int. J. For. Res. 89: 245-252.

Rigling, D., and Prospero, S. 2018. Cryphonectria parasitica, the causal agent of chestnut blight: invasion history, population biology and disease control. Mol. Plant Pathol. 19:7-20.

Sache, Y., Roy, A. S., Suffert, F., and Desprez-Loustau, M. L. 2011. Invasive plant pathogens in Europe. Pages 227-242 in: Biological Invasions: Economic and Environmental Costs of Alien Plant, Animal and Microbe Species. D. Pimental, ed. CRC Press, London.

Santini, A., Ghelardini, L., De Pace, C., Desprez-Loustau, M. L., Capretti, P., Chandelier, A., Cech, T., Chira, D., Diamandis, S., Gaitniekis, T., Hantula, J., Holdenrieder, O., Jankovsky, L., Jung, T., Jurc, D., Kirisits, T., Kunca, A., Lygis, V., Malecka, M., Marcais, B., Schmitz, S., Schumacher, J., Solheim, H., Solla, A., Szabò, I., Tsopelas, P., Vannini, A., Vettraino, A. M., Webber, J., Woodward, S., and Stenlid, J. 2013. Biogeographical patterns and determinants of invasion by forest pathogens in Europe. New Phytol. 197:238-250.

Schoch, C. L., Seifert, K. A., Huhndorf, S., Robert, V., Spouge, J. L., Levesque, C. A., Chen, W. and Fungal Barcoding Consortium Author List. 2012. Nuclear ribosomal internal transcribed spacer (ITS) region as a universal DNA barcode marker for fungi. Proc. Natl. Acad. Sci. USA 109: 6241-6246.

Shaw, C. G., and Florance, E. R. 1979. Scanning electron microscopy reveals differences in surface morphology between basidiospores and conidia of Heterobasidion annosum. Eur. J. Forest Pathol. 9:249-254.

Simpson, E. H. 1949. Measurement of diversity. Nature 163:688.

Stenlid, J., Oliva, J., Boberg, J., and Hopkins, A. J. M. 2011. Emerging diseases in European forests ecosystems and responses in society. Forests 2: 486-504.

Sturrock, R. N., Frankel, S. J., Brown, A. V., Hennon, P. E., Kliejunas, J. T., Lewis, K. J., Warrall, J. J., and Woods, A. J. 2011. Climate change and forest diseases. Plant Pathol. 60:133-149.

Sylvestre-Guinot, G., and Delatour, C. 1978. Recherches sur les variations saisonnières de l'inoculum aérien du Fomes annosus (Fr.) Cooke dans l'est de la France. Ann. For. Sci. 35:151-163.

Takamatsu, S., Braun, U., Limkaisang, S., Kom-un, S., Sato, Y., and Cunnington, J. H. 2007. Phylogeny and taxonomy of the oak powdery mildew Erysiphe alphitoides sensu lato. Mycol. Res. 111:809-826.
Tedersoo, L., Anslan, S., Bahram, M., Pölme, S., Riit, T., Liiv, I., Köljalg, U., Kisand, V., Nilsson, H., Hildebrand, F., Bork, P., and Abarenkov, K. 2015. Shotgun metagenomes and multiple primer pair-barcode combinations of amplicons reveal biases in metabarcoding analysis of fungi. MycoKeys 10: $1-43$.

Tedersoo, L., Drenkhan, R., Anslan, S., Morales-Rodriguez, C., and Cleary, M. 2019. High-throughput identification and diagnostics of pathogens and pests: overview and practical recommendations. Mol. Ecol. Resour. 19: 47-76.

Toju, H., Tanabe, A. S., Yamamoto, S., and Sato, H. 2012. High-coverage ITS primers for the DNA-based identification of Ascomycetes and Basidiomycetes in environmental samples. PLoS One 7:e40863.

Tremblay, E. D., Duceppe, M. O., Béribé, J. A., Kimoto, T., Lemieux, C., and Bilodeau, G. 2018. Screening for exotic forest pathogens to increase survey capacity using metagenomics. Phytopathology 108:1509-1521.

Vettraino, A. M., Roques, A., Yart, A., Fan, J. T., Sun, J. H. and Vannini, A. 2015. Sentinel trees as a tool to forecast invasions of alien plant pathogens. PLoS One 10:e0120571.

Videira, S. I. R., Groenewald, J. Z., Nakashima, C., Braun, U., Barretto, R. W., de Wit, P. J. G. M., and Crous, P. W. 2017. Mycosphaerellaceae: chaos or clarity? Stud. Mycol. 87:257-421.

Weber, J. 2010. Pest risk analysis and invasion pathways for plant pathogens. N. Z. J. For. Sci. 40:S45-S56.

West, J. S., and Kimber, R. B. E. 2015. Innovations in air sampling to detect plant pathogens. Ann. Appl. Biol. 166:4-17.

White, T. J., Bruns, T. D., Lee, S. B., and Taylor, J. W. 1990. Amplification and direct sequencing of fungal ribosomal RNA genes for phylogenetics. Pages 315-322 in: PCR Protocols: A Guide to Methods and Applications. M. A. Innis, D. H. Gelfand, J. J. Sninsky, and T. J. White, eds. Academic Press, Cambridge, MA.

Wieczorek, T. M., Jørgensen, L. N., Hansen, A. L., Munk, L., and Justesen, A. F. 2014. Early detection of sugar beet pathogen Ramularia beticola in leaf and air samples using qPCR. Eur. J. Plant Pathol. 138:775-785.

Woo, P. C. Y., Leung, S. Y., To, K. K. W., Chan, J. F. W., Ngan, A. H. Y., Cheng, V. C. C., Lau, S. K. P., and Yuen, K. Y. 2010. Internal transcribed spacer region sequence heterogeneity in Rhizopus microsporus: implications for molecular diagnosis in clinical microbiology laboratories. J. Clin. Microbiol. 48:208-214.

Yang, R. H., Su, J. H., Shang, J. J., Wu, Y. Y., Li, Y., Bao, D. P., and Yao, Y. J. 2018. Evaluation of the ribosomal DNA internal transcribed spacer (ITS), specifically ITS1 and ITS2, for the analysis of fungal diversity by deep sequencing. PLoS One 13:e0206428.

Zeng, Q. Y., Westermark, S. O., Rasmuson-Lestander, A., and Wang, X. R. 2006. Detection and quantification of Cladosporium in aerosols by realtime PCR. J. Environ. Monit. 8:153-160.

Zhao, Y., Tsang, C. C., Xiao, M., Cheng, J., Xu, Y., Loo, S. K., and Woo, P. C. 2015. Intra-genomic internal transcribed spacer region sequence heterogeneity and molecular diagnosis in clinical microbiology. Int. J. Mol. Sci. 16: 25067-25079. 